\title{
Free Radicals, Neuronal Death and Neuroprotection
}

\author{
Diana Gallego, Manuel Rojas and Camilo Orozco \\ Departamento de Ciencias para La Salud Animal \\ Facultad de Medicina Veterinaria y de Zootecnia \\ Universidad Nacional de Colombia, Sede Bogotá \\ Colombia
}

\section{Introduction}

The Reactive Oxygen Species (ROS) and the Reactive Nitrogen Species (RNS) are highly reactive molecules participating as mediators in biological processes such as metabolic cellular respiration, neurotransmission, translation and transcription gene, and inflammatory-type reactions among others (D. Almaguer \& L.E. Almaguer, 2006; Boots et al., 2008; Uttara, 2009). Additionally, these molecules have the capacity to interact with nucleophilic centers of biomolecules by modulating their activity or by irreversibly modifying them in order to generate different kind of radicals (D. Almaguer \& L.E. Almaguer, 2006).

The main oxygen radicals are the hydroxyl $(-\mathrm{OH})$, the superoxide anion $(\mathrm{O} 2-)$, and the hydrogen peroxide $(\mathrm{H} 2 \mathrm{O} 2)$, while the main nitrogen radical is the nitric oxide $(\bullet \mathrm{NO})$, but also, it is known that the ROS can interact with -NO generating new species with high oxidizing power (Martinez et al., 2010). In aerobic systems most of the ROS come from the mitochondrial oxidative metabolism, where $1-2 \%$ of the oxygen is converted into free radicals (Uttara et al., 2009). Other less important sources of ROS are the autoxidation of catecholamines and hemoproteins that occurs in the cytoplasm, nuclear membrane, endoplasmic reticulum and peroxisomes (Boots et al., 2008; Martínez et al, 2010). The concentration of ROS or RNS in organisms is determined by the balance between the rate of production of reactive species and the elimination rate of these compounds by the action of enzymes and antioxidants (AO) (Dorado et al., 2003). Thus, under conditions of physiological homeostasis, a balance exists between the cellular processes that contribute to the production of ROS / RNS, and those factors such as superoxide dismutase (SOD), catalase (Cat) and glutathione peroxidase (GPx), which contribute to their elimination (Dorado et al., 2003; Martínez et al., 2010). Thus, alterations in the balance between these systems, pro-oxidants and antioxidants can lead to intracellular accumulation of free radicals (FR), causing oxidative stress states (Dorado et al., 2003; Kelsey, et al , 2010; Uttara, 2009).

Specifically, oxidative stress and redox imbalance is the combined result of excessive formation of oxidant species (ROS/RNS) and/or a decreasing in the efficiency of endogenous antioxidant systems. Thus, the combination of these factors converge in damaging to biomolecules such as DNA, RNA, proteins, carbohydrates and lipids. This probably initiate processes of mitochondrial dysfunction and excitotoxicity (Kelsey, et al., 
2010; Dorado et al., 2003), which in turn results in structural and functional alterations of organic macromolecules, leading the affected cells to degenerative processes and cell death by necrosis or apoptosis (D. Almaguer \& L.E. Almaguer, 2006; Gonzalez et al. 1999; Martinez et al., 2010). The deleterious effects of ROS on cell integrity, eventually may drive or participate in the development of diseases or pathological processes such as atherosclerosis, cancer, diabetes, rheumatoid arthritis, ischemia-reperfusion syndrome, cardiovascular disease, chronic inflammatory processes, shock Blackwater and other degenerative diseases in humans and animals (Freidovich, 1999; Fang et al., 2002). However, is hard to establish whether these reactive species represent a primary etiologic factor or product from the damaged tissue (Gonzalez et al., 1999).

The biochemical composition of the brain tissue makes it especially susceptible to the action of ROS/RNS, as it contains a pool of unsaturated lipids which are suitable to oxidative modification and lipid peroxidation. The double chains of unsaturated fatty acids are targeted for attack by free radicals, which initiate a cascade or chain reaction that damages these acids (Butterfield et al, 2002). Several researchers consider the brain as an organ highly susceptible to oxidative damage, and several studies have demonstrated how easy occurs the peroxidation of brain cell membranes (Chance, 1979). Also, the brain seems to be more susceptible than other organs to peroxidation, this is probably due to its high oxygen requirements, it uses $20 \%$ of the total oxygen intake, while weighing only $2 \%$ of the total body weight. Neuronal cells are considered the most susceptible cells to oxidative damage, owing to their low antioxidant activity in comparison to other tissues, as well as the high content of methyl ions in certain brain regions (Floyd, 1992). In this regard, some authors have suggested that the continuous state of oxidative stress may produce specific structural alterations of proteins, leading to abnormal protein aggregate formation, which is responsible for perpetuating oxidative damage. In fact, these abnormal proteins are considered as molecular markers of neurodegenerative diseases such as Alzheimer, Parkinson, and Cognitive Dysfunction Syndrome in geriatric dogs (Gallego et, al., 2010a, 2010b).

There are several risk factors involved in the development of these neuropathologies, one of them is the aging process "per se". In this regard, when the production of ROS / RNS has an exaggerated and prolonged increasing, and the antioxidant response is not enough, the system reach a different point of equilibrium (homeoresis, rather than homeostasis). This equilibrium is accompanied by high concentrations of free amino acids and differences in gene expression patterns, allowing survival but causing irreversible neuronal damage in the long term (Rivas et al., 2001). The original hypothesis of the free radicals in aging was proposed by Harman Gerschman and Harman in the 50's (Sohal, 1993). The central dogma of this theory is that during the aerobic metabolism there is an incidental and uncontrollable production of oxygen radical species. Then, these species promote reactions damaging the macromolecules. This irreversible damage accumulates over time and results in a gradual loss of functional capacity of the cells (Hayflick, 1993). According to recent studies this might be related to neuronal processes of senescence (Passos, et al, 2010).

\section{Oxidative stress (OS) and neurodegenerative diseases (ND)}

There are plenty scientific evidence that considers the brain tissue as a preferential target for the accumulation of ROS and RNS, thereby triggering oxidative stress chronic conditions, which lead to injury and degeneration of neuronal cells (Contestabile, 2001). It has been 
reported that the nervous system is rich in iron $(\mathrm{Fe} 3+)$ and unsaturated fatty acids (Halliwell, 2001), this is one of the main features that make this organ particularly sensitive to oxidative stress. Thus, the high lipid content of nervous tissue and its high metabolic activity make it particularly vulnerable to oxidative damage (T.M. Dawson \& V.L. Dawson, 1996). It has been reported that iron is essential in the brain, particularly during development, but high amounts can lead to the generation of damage to brain cells, because Fe $3+$ can lead to oxidative stress by catalyzing the formation processes of ROS (Butterfield et al, 2002; Gerlach et al, 1994). In addition, the brain consumes a high proportion of the total oxygen, since the energy it uses comes almost exclusively from oxidative metabolism which occurs in the mitochondrial respiratory chain located in the bodies, dendrites, axons and synaptic buttons of cells neural, where the ATPase maintains the ionic gradient across the neuronal membrane (Pavón et al., 1998). Another reason that explains why ROS are particularly active in the brain is that in this tissue, the metabolism of the aminoacids and neurotransmitters acts as an important source of these highly reactive molecules (Uttara et al., 2009). Thus, considering that this organ contains low levels of protective enzymes and other enzymatic antioxidants, it is easy to understand why their susceptibility (Contestabile, 2001).

Although oxidative stress is not the direct cause or the etiological factor responsible for the neuropathologies, it is known that it induces toxic effects by oxidizing lipids, proteins, carbohydrates and nucleotides. This causes accumulation of intracellular aggregates, mitochondrial dysfunction, excitotoxicity and apoptosis. Formation of modified lipids by oxidation can cause cellular dysfunction and death in postmitotic cells. Likewise, the peroxidation of polyunsaturated fatty acids in cell membranes, initiates a cumulative deterioration of membrane functions and causes a decrease in flow, reduction in the electrochemical potential and increased permeability of the membrane. Similarly, oxidation causes changes in the structure of some proteins and the formation of protein aggregates. These abnormal proteins induce oxidative damage that has been observed in neurodegenerative diseases as $\mathrm{AD}$ and PD. On another hand, ROS also can affect both glial cells and neuronal cells, which exhibit a particular sensitivity to free radicals and therefore are prone to cell degeneration processes (Gilgun-Sherki et al., 2001). For example, there is a biological phenomenon known as "selective neuronal vulnerability", which is involved in the response of different neuronal populations against neurodegenerative conditions. For example, neurons in the entorhinal cortex, the CA1 region of hippocampus, frontal cortex and amygdala, are highly susceptible populations to neurodegeneration associated with oxidative stress in Alzheimer's disease (AD) (Braak et al., 1991; Hyman et al, 1984; Terry et al, 2001).

The relationship between aging and neurodegenerative diseases is more than evident. This is supported by recent investigations that have observed that during the aging process there is an increase in the formation of $\mathrm{H} 2 \mathrm{O} 2$ that alters the conditions of the electrons flow in the transport chain, facilitating their 'escape' of normal stream flow. This leads the neurons to suffer the harmful effect of free radicals. Moreover, studies performed by Sohal, et al., 1993, Benzi \& Mareti, 1995, and others, have postulated that ROS can inflict damage to the mitochondrial inner membrane, the components of the electron transport chain or the mitochondrial DNA (mtDNA). Oxidative stress further increases ROS production and, consequently, damage to the mitochondria, creating a cycle that perpetuates the effects of ROS (González et al., 1999). Thus, it is obvious because aging itself is a key factor in diseases such as $\mathrm{AD}$ or $\mathrm{PD}$; since the increase of oxidative damage, the progressive mitochondrial 
failure accumulated with aging, and coupled with the characteristics of brain, make aging itself a common risk factor in neurodegeneration. Another fact that may explain the relationship between neurodegeneration and aging is that during aging can occurs certain level of iron accumulation, which increases oxidative stress. This occurs mainly through the Fenton reaction, where the production of highly reactive hydroxyl radicals ends up causing damage to DNA, lipids and proteins (Ang et al., 2010; González et al., 1999; Uttara et al., 2009).

In addition to the accumulation of free radicals that can occurs in the brain of individuals with ND, it is also clear that the antioxidant systems decrease during the aging process. Then, the action of ROS turns up in a process even more damaging to neuronal tissue. Scientific data suggest that all this deleterious effect seems to be magnified by pathological proteins such as beta-amyloid in AD and alpha-synuclein in PD, which act as initiators and perpetuators of the intraneuronal oxidative stress, generating injuries and disease-specific symptoms.

\subsection{Alzheimer disease}

According to some authors, the ROS in AD induce a prolonged increase pro-oxidant state (Benzi \& Mareti, 1995). This statement is supported by clinical and experimental evidence (for example, high concentrations of $\mathrm{Fe}$ and $\mathrm{Cu}$ identified in the brains of some patients with $\mathrm{AD})$, showing that ROS cause neuronal death and other neuropathological changes associated with this disease (González et al., 1999; Ramesh et al., 2010). However, the role of oxidative processes in $\mathrm{AD}$ is still a matter of debate, with conflicting and divergent data in the literature, which could be related to the difficulty of directly measuring the activity of ROS in biological systems due to their short half-life and its high reactivity (Gonzalez et al., 1999).

Several studies have identified the capacity of the protein $\beta A$ as a chelating agent for transition metals ( $\mathrm{Cu} 2, \mathrm{Zn} 2$ and Fe3). Regarding this, it is important to note that the binding of $\mathrm{Cu} 2$ and $\mathrm{Fe} 3$ provides free radicals $\mathrm{OH}{ }^{\circ}$, and toxic chemical reactions, due to the altered state of oxidation of these two metals, causing the appearance of catalytic $\mathrm{H} 2 \mathrm{O} 2$ in the presence transition metal (Uttara et al., 2009). Additionally, the Fe3 in AD neurofibrillary plaque accumulates (NFT) and depots $\beta$ A, which probably explains the evidence that suggests increased levels of $\mathrm{Zn}$ (II), Fe (III) and $\mathrm{Cu}$ (II) in the neuropil and senile plaques (Ramesh et al., 2010). Moreover, it appears that the Fe3 directly involved in plaque formation $\beta \mathrm{A}$, and thus indirectly in the formation of ROS, as it promotes amyloidosis by modulating the ability of the $\alpha$-secretase to cleave the amyloid precursor protein (APP), or to facilitate the aggregation of $A \beta$.

In 1994, Behl C. and colleagues showed that toxicity in AD is associated with the $\mathrm{A} \beta$ protein, which causes increased production of $\mathrm{H} 2 \mathrm{O} 2$. These authors also showed that catalase blocks the toxicity of $\mathrm{A} \beta$, which allows us to understand how the $\mathrm{H} 2 \mathrm{O} 2$ and its derivatives such as $\mathrm{OH}$-radical, cause lipid peroxidation leading to neuronal cell death in this disease (González et al., 1999). In addition, hemoxigenasa1 the $\mathrm{Cu} \backslash$ ZnSOD and MnSOD, have been identified in neurofibrillary tangles of human brains with $\mathrm{AD}$, suggesting a close interaction between ROS and the products from these enzimes. It has also been suggested that cellular toxicity of $\beta$ A that is specifically related to damage by ROS or its products, generates insoluble protein aggregates, as is known, is a crucial event in AD (González et al., 1999).

Moreover, there is indirect evidence that ROS can relate to AD. For example, some dietary factors such as saturated fatty acids, high calories and heavy drinking have been reported as 
factors that may increase the risk of dementia and AD. In contrast, consumption of foods with antioxidants such as fruits, proteins rich in methionine and vitamins have been identified as protective factors against the disease. In this sense, it is possible that the variation in the diets may be associated with the prevalence of AD by geographic area, as several studies have suggested a link between nutrients of each diet and the presence of cognitive changes. However, it is necessary to confirm this experimentally (Ramesh et al., 2010).

\subsection{Parkinson disease}

Experimental data suggest a relationship between the PD and two mitochondrial-specific conditions, dysfunction and oxidative damage to neuronal mitochondria. This assertion is supported by research suggesting mitochondrial dysfunction and impairment of mitochondrial complex I activity in the neurons of the substantia nigra and frontal cortex in PD patients. In addition, several genes whose mutations or polymorphisms increase the risk of developing PD are related to mitochondrial function. In this regard, dysfunction of mitochondrial complex I, becomes important, since its inhibition creates a biochemical environment that increases the production of FMNH semiquinone flavin, which increases the generation of $\mathrm{O} 2$ and in turn, the latter promotes lipid peroxidation, damage oxidative protein and protein nitration mediated by peroxynitrite (ONOO-) and nitrosylation. This is a process leading neurons to apoptosis and $\alpha$-synuclein aggregation with subsequent death of dopaminergic neurons. (Navarro \& Boveris, 2008, 2010).

According to Dorado et al., 2003, the substantia nigra has characteristics that tend to make it more vulnerable to attack by ROS. These features include low levels of glutathione and vitamin E, high levels of free iron (prooxidant), mono amine oxidase (MAO generates ROS), - NO (radical neurotoxic pro-oxidant) and neuromelanin. The neuromelanin is a black pigment found in certain subpopulations of monoaminergic neurons, and is the result of auto-oxidation, condensation and polymerization of dopamine and its oxidation products. Neuromelanin binds to any neutralizing reactive species, but can become a reservoir of toxic under certain conditions (oxidative attack, low levels of glutathione) releases these reactive species. Thus, neurons that contain greater amounts of neuromelanin in the substantia nigra pars compacta die more easily.

Glutathione (GSH) which is the most important intracellular molecule for the removal of hydroperoxides in the brain, is decreased in Parkinsonian patients. This could be related to the increased concentration of MDA (a marker of lipid oxidation). One of the facts that suggests the role of ROS in this disease is that they have identified high levels of glycosylation end products (AGE resulting from impaired glucose oxidation and cause irreversible oxidation of protein) in the substantia nigra and cortex. Also, it appears that a factor associated with oxidative damage is that the distribution of transition metals in the brain shows large regional differences, so that regions with large amounts of iron (which is easily oxidized) as the substantia nigra are at risk of suffer a more aggressive oxidative attack (Dorado et al., 2003). However, this is not the only mechanism to explain why dopaminergic neurons are especially sensitive to oxidative stress, because its high metabolic rate and the oxidation of dopamine, either by autoxidation or by the metabolic pathway by means of the MAO (Dorado et al., 2003), they represent a major source of ROS. Likewise, dopamine may act as metal chelator electron donors, and owing to its tendency towards reduction can initiate the Fenton reaction to generate $\mathrm{H} 2 \mathrm{O} 2$. Some evidence suggests that mutations in the protein $\alpha$-synuclein play a crucial role in 
modulating the activity of dopamine, but negatively, initiating neuronal cytoplasmic accumulation and interaction of dopamine with iron to cause the production of ROS (Uttara et al., 2009).

\section{Cellular defense systems against oxidative stress (OE)}

ROS and RNS molecules are well known for their deleterious effects on cellular integrity and their relation to different neurodegenerative diseases such as described in the previous section. However, it is important to note that these molecules also play a physiological role, quite distant from the aforementioned pathological role. In homeostatic physiological conditions their responses participate in cell signaling systems such as in the defense response against infectious agents and induction of mitogenic responses (Valko et al., 2007). These cellular responses bring the intra and extracellular environments to a continuous exposure to FR (González et al., 1999). Owing to this condition, aerobic organisms have evolved specific defense mechanisms, programmed to form cell protective barriers, which allow them to restrict the harmful effects of free radicals and neutralize the damage caused by the action of these reactive species (D. Almaguer \& L.E. Almaguer, 2006; Cadenas, 1997; Contestabile, 2001; Perez et al., 2008; Valko et al., 2007; Vian et al., 1999). These mechanisms refer to antioxidants. These are molecules of different weights whose function is basically delay or inhibit oxidation. The mechanism is to transfer electrons to the reactive species to saturate its electron affinity, and thus, maintain ROS at a level compatible with metabolic processes and cellular functions (D. Almaguer \& L.E. Almaguer, 2006; Contestabile, 2001; Viant, 1999).

\subsection{Classification of the main antioxidant systems}

Taking into account specific aspects of antioxidants, such as their chemical nature, mechanism of action or origin, several strategies have been proposed for classification. According to Gilgun-Sherki et al.2008, these compounds can be classified into two major groups: antioxidant enzymes and low molecular weight antioxidants. To the first group belong some antioxidant enzyme systems derived from enzymes as cytochrome oxidase, superoxide dismutase (Cu-ZnSOD and MnSOD), catalases and peroxidases such as glutathione peroxidase and glutathione reductase (Dorado et al., 2003). The group of low molecular weight antioxidants involves a variety of antioxidants, so some authors have subclassified this group into two: indirect antioxidants (eg, chelating agents) and direct antioxidants. The latter group is of great importance in combating oxidative stress and contains hundreds of components, however, only a minority of these molecules such as glutathione and NADPH are synthesized by the cell itself.

Another classification for antioxidant systems, refers to its source. In this sense, we can identify endogenous antioxidants and antioxidant of exogenous origin. The first group are vitamins such as ascorbic acid, tocopherol and retinoic acid also found glutathione in its reduced form, coenzyme Q10, melatonin, uric acid and lipoic acid. Also are included some isoforms of the enzyme superoxide dismutase (copper/zinc SOD, manganese SOD, extracellular SOD), catalase and glutathione peroxidase (Gilgun-Sherki et al.,2008; Chan, 2001; Contestabile, 2001). With respect to the group of antioxidants of exogenous origin, ie those that can only be obtained from external sources, we should mention some substances such as acetyl cysteine and carotenoids, which act as precursors of endogenous antioxidant type (Gilgun-Sherki et al.,2008; Chan, 2001; Contestabille, 2001). 
Due to this variety in the classification of antioxidants, a new classification has been proposed recently, which seeks to involve the full range of antioxidants based on aspects such as chemical nature and mechanism of action (Cui et al., 2004; Pérez, A. et al., 2008). Such a classification sets these compounds into the following groups:

1. Antioxidant enzymes: They act on specific ROS, in order to change them into less harmful molecules. Examples of such enzymes are SOD, CAT, and GPx.

2. Preventive Antioxidants: These bind to promoters of oxidation and sequester transition metal ions such as iron and copper, which contain unpaired electrons and greatly accelerate the formation of free radicals. Examples of such antioxidants are transferrin and lactoferrin (Pauls \& Thompson, 1980). Also, ceruloplasmin Cu hijacking to prevent the formation of free radicals from peroxides, catalyzes the oxidation of ferrous ions to ferric ions due to its ferroxidase activity, and increases the binding of iron to transferrin. In addition, the haptoglobins that bind to hemoglobin, hemopexin that binds heme groups and albumin binds to heme and Cu (Benedetti et al., 1988).

3. Antioxidant ROS sequestrant: These inhibit the initiation of chain reactions of free radicals or break the chain of spreading it. The main intracellular sequesters are vitamin E, carotene and coenzyme Q (Murthy, 2001), while extracellular sequesters include protein systems, and water-soluble compounds such as ascorbic acid, uric acid and bilirubin (Cui et al, 2004; Frei et al., 1988; Pérez, A. et al., 2008;).

4. Nutritional Antioxidants: Diet is the major source of substances with antioxidant properties or elements for the synthesis of antioxidant enzymes. Several metals (copper, zinc, selenium, manganese, iron) are involved as components or cofactors of numerous enzymes antioxidants, and certain vitamins (ascorbic acid, $\alpha$-tocopherol and $\beta$-carotene, folic acid) act as a sequestrant of ROS (Pérez, A. et al., 2008).

\subsection{Mechanisms of neutralization of ROS}

The different antioxidant systems work in a coordinated manner, following a series of metabolic processes where $\bullet$ O2-metabolized by superoxide dismutase SOD generates $\mathrm{H} 2 \mathrm{O} 2$, and this in turn is metabolized to $\mathrm{H} 2 \mathrm{O}$ and $\mathrm{O} 2$ by a catalase or glutathione peroxidase, which act as coupled with glutathione reductase (Dorado et al, 2003). However, it is difficult to think of a single molecular mechanism that acts as a regulator of the generation and the effects of FR, so some authors, for instance, Cadenas, 1997, propouse at least three types of molecular mechanisms that underlie the activities of various antioxidants. Such mechanisms are: (a) a process involving the transfer of the radical nature of ROS, together with the formation of a reactive radical, an antioxidant derived previously, (b) a similar process in which the transfer of the radical, and the formation of a stable or inert radical is carried out through enzymatic activity, and (c) mechanisms of action of small molecules that mimic the activity of enzymes such as SOD and GPx. These mechanisms describe to some extent the action of a variety of molecules with antioxidant properties, for example, enzymes such as SOD, CAT and GPx, which are responsible for initiating the process of neutralization of ROS by the dismutation of $\mathrm{O} \bullet 2$ to $\mathrm{H} 2 \mathrm{O} 2$ (D. Almaguer \& L.E. Almaguer, 2006). Other defense mechanisms used by different antioxidants include, recycling of ROS/RNS or their precursors, inhibition of ROS formation, binding of metal ions required for catalysis of ROS generation and activation of endogenous antioxidant defenses (Gilgun-Sherki et al.,2008).

According to some researchers (Halliwell, B., 1994, 1997; Cadenas, 1997; Dorado et al, 2003), the protective efficiency of this variety of antioxidants, is somewhat dependent on the type 
of ROS generated, the place where they are produced (physical barriers like the blood-brain barrier permeability reduce many antioxidants) and the severity of cell damage.

\section{Antioxidants and neurodegeneration}

During the last decades in many populations around the world there has been a notable increase in the number of adults over 60's (United Nations [ONU], 2009). Consequently, there has been an increase in the incidence and prevalence of various diseases affecting the elders. Among this group of diseases, the neurodegenerative type have become very important, especially in industrialized countries, which are listed as the third leading cause of death after cardiovascular diseases and cancer (Boyd, 2000; Gallego et, al., 2010a; United Nations [ONU], 2009; Segura, 2003; Troenes B, et al 2003). However, the ND related to aging, not only represent a problem for human health because there are substantial data showing that aging also predisposes other species to suffer dementia syndromes. For example, some old dogs can develop neuropathology similar to AD, known as Cognitive Dysfunction Syndrome in Senior Dogs (CDS) or "dog's Alzheimer". This disease affects dogs over 7 years old and due to its clinical and pathophysiological similarities with AD has been proposed as a model for doing research in the field of neurodegeneration, especially in the study of AD (Adams B, et al., 2000; Gallego, 2010b; Overall, 2001; Ruehl et al., 1995).

As already mentioned, the incidence of ND increases with age, however, we must clarify that the risk of having them can be determined, partially, by factors such as lifestyle, obesity, metabolic syndrome, genetic susceptibility, predisposing medical factors and increased oxidative stress, among others, but the last one is the main factor related to the presentation of these diseases (Contestabile, 2001; James et al., 2009; Kelsey et al., 2010; Uttara et al., 2009;). In this sense, today it seems clear the role of oxidative stress during the onset and course of ND associated with aging (Meydani et al., 1998; Passos et al., 2010). So, recognizing this fact has allowed us to identify therapeutic targets where the activation of cellular mechanisms of antioxidant type appear to be a suitable option for the treatment of neurodegenerative diseases such as AD, PD and CDS (Casetta et al., 2005; James et al., 2009, Contestabile, 2001). In general terms, the main goal of the antioxidant therapy for these diseases is to interrupt or modulate the interaction of pathological neuronal protein (A $\beta$ protein and Tau protein) with redox metals. This is in order to prevent damage or decomposition of metalloenzymes, and innate antioxidant systems by promoting homeostasis of metals and minimizing the OE and its effects (Uttara et al., 2009). Additionally, several studies suggest that increasing cellular protection through the use of antioxidants could be beneficial for maintaining or reducing the rate of neuronal death during the course of certain ND, such as PD (Casseta et al., 2005; Kelsey et al., 2010).

Thus, taking into account the growing interest in antioxidant therapy for the treatment and/or prevention of ND, and considering that diet is a main source of natural AntiOxidants (AO), then we present a systematic review of scientific evidence showing the action and effect of some food products on the course or the beginning of the characteristic lesions of this type of pathology.

\subsection{The role of diet as a preventive factor against the development of ND}

Given that the lifestyle and the type of diet can act as important risk factors for the emergence of various diseases (Kalaria et al., 2008), the relationship between a particular diet and its effects long-term research center have been some authors who seek through diet 
and antioxidant compounds, mechanisms to develop or enhance protective responses against a constant state of oxidative stress. In addition, people generally consider that there are several advantages to the use of antioxidants, in fact, there are a consumer culture around these compounds, where people attempt to consume diets rich in antioxidants and/or supplement their diet with one or more of these substances to "improve living conditions for the geriatric stage" (Mullie et al., 2009). Several studies have shown that diet has a long-term effect on general health (Leibson et al., 1997; Uttara et al., 2009; Vermeer, et al., 2003), acting as a principal source of natural antioxidants due to its ability to provide a variety of molecules that activate or enhancer the action of some endogenous antioxidants (Sun et al., 2008). In this sense, it is important to consider the effect of these molecules on processes of neuroprotection, since according to some reports, the diet also has the ability to extend human cognitive longevity (Peter, et al, 2004; Casseta, 2005, Glade, 2010; Ramesh et al., 2010). There are several antioxidant research in the field of ND, such as AD and PD, but despite the variability of results and poor clinical trials, diets rich in vitamins and other natural antioxidants still seem to be publicly recognized for their action as useful supplements in reducing risk of suffering some types of dementia (Kamphuisa \& Scheltensb, 2010).

Evidence of this can be seen in some studies indicating that Indian diets, which contain spices like red chilli, coriander and turmeric (plant widely used as food preservative and medicinal), apparently reduced the prevalence of patients with AD in India, since its incidence is 4.4 times lower compared to countries like the U.S. (James et al., 2009; Ramesh et al., 2010). Additionally, some reports indicate supplementing diets high in fat that usually lead to the development of cardiovascular diseases with a high intake of dietary antioxidants, such as polyphenols, may reduce the risk of disease. Likewise, consumption of nutritional substances such as berries, nuts or fish oil can dramatically impact on the aging brain, possibly leading to improved motor and cognitive skills (James, et al, 2009). In this context, the interest in finding low-cost therapeutic alternatives that improve living conditions and reduce the risk of age-related diseases has led to the identification of a growing list of antioxidant supplements as Vitamins $C$ and $E, \beta$-carotene, coenzyme $Q$, ascorbate and polyphenols, among others (Burton \& Ingold, 1989, 1990; Kelsey et al., 2010).

\subsection{Scientific evidence of AO supplementation in the treatment of ND}

Natural antioxidants can act as a therapeutic tool against excess ROS, because several of them have a high ability to cross the blood brain barrier (Uttara et al., 2009), and can activate various antioxidant mechanisms in the brain in order to create conditions to achieve and maintain the neuronal homeostasis (Gilgun-Sherki et al., 2001). However, an antioxidant substance that has some use in preventing the ND must have some additional capabilities to its ability to sequester free radicals. For example, one of the main AO found in mammalian cells is glutathione (GSH), however, this substance, despite its large capacity anti FR can't be directly used for supplementation, due to their inability to cross the bloodbrain barrier and reach the brain tissue (Witschi et al., 1992). Despite this, some of its precursors or analogs have been tested in various animal models (Contestabile, 2001). Thus, studies such as Martinez, et al., 2000, suggest that long-term supplementation with GSH precursors such as $\mathrm{N}$-acetylcysteine can partially restore the impaired memory and decreased mitochondrial lipid peroxidation, characteristic of aging process. (Contestabile, 2001; Prasad et al., 1999). 
The use of AO decreases oxidative damage and also reduce the cognitive decline associated with age, this in both human and animal models (Joseph et al., 1998; Milgram et al., 2002). Examples are the studies conducted in geriatric dogs, which indicate that oxidative damage may be related to cognitive dysfunction and that long-term treatment with $\mathrm{AO}$, with a behavioral enrichment program, reduce cognitive decline in dogs CDS (Cotman et al., 2002; Gallego et al, 2010a; Head E, 2002; Landsberg, 2005). Also, some authors argue that the intake of fruits and vegetables may reduce the risk of cognitive decline associated with aging in rodents, dogs and even humans, attributing that property to the capabilities of some antioxidants and anti-inflammatory compounds found in these foods (Araujo et al., 2005; Gallego et al., 2010; Landsberg, 2005; Opii et al., 2008).

With regard to vitamins, their results seem contradictory. Studies conducted with various vitamins have suggested these compounds as potential protective factors against states of neurodegeneration. Thus, recently demonstrated that supplementation of Vitamin E 500UI long term in the rats diet can protect against cognitive decline associated with aging (Morris, et al., 2005; Peterson et al., 2005). However, other studies in this category showed contrasting results, for example, a research conducted by Young KW, et, al, 2005, which included subjects with mild cognitive impairment, who were given a daily dose of 2.000UI of Vitamin E and $10 \mathrm{mg}$ of donepezil (compound with anticholinergic activity) or a placebo for a period of three years. The results of this study showed that the overall rate of progression from mild cognitive impairment to clinical expression of $\mathrm{AD}$ was $16 \%$ per year, and no difference was found between the subjects who were administered placebo, and subjects who received vitamin E, suggesting a disagreement over the validity of vitamin supplements to patients with AD (Kelsey et al., 2010).

With respect to the $\mathrm{PD}$, some of the $\mathrm{AO}$ compounds that have been suggested as protective factors include vitamins A, C $(3000 \mathrm{mg} / \mathrm{d})$ and E $(3200 \mathrm{mg} / \mathrm{d})$ (Fahn, 1991). Several epidemiological studies have shown that consumption of these vitamins may improve cognition and reduce the risk of developing clinical symptoms characteristic of this disease (Masaki et al., 1994). Likewise, the study by Chen et al, 1997, showed that administration of coenzyme Q10 improved clinical symptoms in patients with mitochondrial encephalopathy. Similarly, Birkmayer, et al, 1990, in a study of 415 patients with PD showed that administration of a dose of $1.4 \mathrm{mg} / \mathrm{kg} \mathrm{NADH}$ can be an effective therapeutic tool in the treatment of PD. According to some authors, the efficiency of AO such as vitamins E and C, is the most convincing evidence of the involvement of free radicals in PD. However, in order to determine the efficacy of an antioxidant treatment, it is necessary to perform additional studies including high doses of vitamin E $(3200 \mathrm{mg} / \mathrm{d})$ in combination with vitamin C $(3000 \mathrm{mg} / \mathrm{d})$, before the administration of levodopa in patients with early PD (Fahn, 1991; Rao \& Balachandran, 2002).

Acetyl-L-carnitine as a metabolite of vitamins involved in the process of synaptic transmission and has a potent neuroprotective effect can reduce the structural damage caused by states of oxidative stress in neurons. Neuroprotective capacity of this metabolite is evidenced through the increase in resistance to oxidation of cellular components such as mitochondrial RNA, and various proteins (Sharman et al., 2002; Poon et al., 2006). Previous research has shown that the brains of old rats respond positively to the diets supplemented with acetyl-L-carnitine in the long term. This effect is generated by activating the expression of intracellular enzymes such as GSH and SOD, which leads to a reduction in the formation of 4-hydroxynonenal in the mitochondria, and thus decreases the degree of carboxylation and oxidative nitrosylation mitochondrial protein (Calabrese, et al., 2006; Poon et al., 2006). 
Additionally, some authors suggest that the severity of demyelination and neuronal necrosis is reduced in brain areas such as cortex, hippocampus, cerebellar cortex and optic nerve of rats consuming acetyl-L-carnitine (Ramacci et al., 1998; Glade, 2010). Likewise, the use of acetyl-L-carnitine as a dietary supplement to improve cognitive longevity has been demonstrated by the results of a study by Passeri et al., 1990, in which two parallel groups and assessed homogeneous subjects of both sexes aged 65 years and with mild cognitive functions. One group was supplemented with 2 gr/day of acetyl-L-carnitine for three months, while the other group was treated with a placebo. The group of patients treated with acetyl-L-carnitine showed a significant improvement in learning abilities, and longterm memory skills, suggesting the therapeutic importance of this metabolite for the treatment of geriatric patients with mental disfunction.

Besides the natural $\mathrm{AO}$, there is also a growing list of synthetic $\mathrm{AO}$ that have been widely studied, for example, conjugated forms of the enzymes SOD and CAT (Greenwald, 1990) and supplements of selenium (Parnham et al., 1991). Similarly, there is growing evidence that give, some drugs with different therapeutic uses to neuroprotection such as probucol (hypocholesterolemic) and salicylates, a certain capacity as recycler of free radicals under experimental conditions (Cui et al., 2004; Juliano et al., 1995; Zhao et al., 1995).

However, despite the existing literature suggesting beneficial effects of $\mathrm{AO}$, there are several questions regarding the therapeutic value that some natural $\mathrm{AO}$ may have compared to pathological processes such as AD and PD. There are conflicting data emerging from research on in vitro and in vivo neurodegeneration models, and some authors argue that the fact that one type of antioxidant molecule is produced physiologically or is taken normally from the diet is not a guarantee that this supplementation can be safe and advantageous therapeutic standpoint, since it must be took into account the physiological regulation of the redox state of the cell (Contestabile, 2001). In conclusion, experimental data are converging in terms of the therapeutic benefits of various natural antioxidants with neuroprotective capabilities, however, according to some authors, there are very few clinical data to demonstrate a clear and lasting effect of this type of treatments. Some possible reasons for such a disadvantage might be specific criteria such as dose, stability, duration of treatment, side effects and ability to cross the blood brain barrier, among others (Contestabile, 2001; James, 2009; Meydani et al., 1998). Because of this, it is essential to expand research on the use of $\mathrm{AO}$ diet supplements compared to the onset and development of ND as AD and PD.

\subsection{Dietary supplements with antioxidant used in the management of ND}

Considering the cascade of degenerative events of diseases such as AD and PD (degradation and abnormal folding of proteins, inadequate energy production in CNS degeneration by oxidative damage, excitotoxicity and inflammation), there is interest in whether the $\mathrm{AO}$, or changes in eating habits can prevent and/or block one or more of these pathways of neurodegeneration in slowing the progression of the disease (Mazzio, et al., 2011). In this regard, several studies have suggested some properties of antioxidants as protective factors against the risk of diseases such as $\mathrm{AD}$ and PD. In addition, it is considered that changes in the concentration of $\mathrm{AO}$ in states of neurodegeneration may be a primary event or secondary to the ingestion of a particular type of diet (Kedar, 2003). Therefore, considering the usefulness of certain $\mathrm{AO}$ and its possible uses in therapy of ND, the following describes some of the main AO that are consumed in the diet or supplemented in order to treat or prevent the onset of neurodegenerative conditions such as AD or PD. 


\subsubsection{Vitamins}

\subsubsection{Vitamin E}

Vitamin E or tocopherol is a powerful antioxidant capable of stopping the spread of the chain reaction of free radicals in the lipid portion of cell membranes, inhibiting lipid peroxidation in plasma membrane phospholipids (Mandel et al., 2003; McCay, 1985; GilgunSherki et al., 2001). There are eight tocopherols with vitamin E activity, and $\alpha$-tocopherol is

\begin{tabular}{|c|c|c|}
\hline Use & Results & Reference \\
\hline $\begin{array}{l}\text { The individual or combined action } \\
\text { of tocopherols are protective } \\
\text { factors against the incidence of AD } \\
\text { and cognitive dysfunction }\end{array}$ & $\begin{array}{l}\text { The different forms of tocopherol that } \\
\text { make vitamin E exert greater } \\
\text { protective effect associated with AD, } \\
\text { compared with } \alpha \text {-tocopherol alone }\end{array}$ & $\begin{array}{l}\text { Morris et } \\
\text { al. } 2005\end{array}$ \\
\hline $\begin{array}{l}\text { Supplementation with vitamins } E \\
\text { and } C \text { to reduce lipid peroxidation } \\
\text { in patients with } A D \text {. }\end{array}$ & $\begin{array}{l}\text { Increases in plasma levels of vitamin } \\
\text { E does not affect the oxidation } \\
\text { resistance of lipoproteins, it is } \\
\text { necessary to use combinations of the } \\
\text { two vitamins. }\end{array}$ & $\begin{array}{l}\text { Kontush et } \\
\text { al. } \\
{[281]}\end{array}$ \\
\hline $\begin{array}{l}\text { Supplementation with } 3000 \text { IU / } \\
\text { day vitamin E and C can delay the } \\
\text { onset of symptoms associated with } \\
\text { dopamine deficiency in PD } \\
\text { patients }\end{array}$ & $\begin{array}{l}\text { Increase the time interval between } \\
\text { the onset of the disease and the need } \\
\text { for treatment with L-dopa in } 75 \% \text { of } \\
\text { patients. }\end{array}$ & $\begin{array}{l}\text { Fahns A, } \\
1998\end{array}$ \\
\hline $\begin{array}{l}\text { Combination of supplements of } \\
\text { vitamins } C \text { and } E \text { affect the } \\
\text { prevalence and incidence of AD. }\end{array}$ & $\begin{array}{l}\text { The combined use of vitamin } \\
\text { supplements showed a decrease in } \\
\text { the incidence and prevalence of AD } \\
\text { in a population of } 5092 \text { individuals }\end{array}$ & $\begin{array}{l}\text { Zandi et } \\
\text { al., } 2004\end{array}$ \\
\hline $\begin{array}{l}\text { Supplementation with } 2000 \mathrm{IU} / \\
\text { day vitamin E reduces the EO } \\
\text { implicated in the pathogenesis of } \\
\text { AD. }\end{array}$ & $\begin{array}{l}\text { Treatment delays functional } \\
\text { impairment in patients with mild } \\
\text { Alzheimer's disease. }\end{array}$ & $\begin{array}{l}\text { Sano et al., } \\
1997\end{array}$ \\
\hline $\begin{array}{l}\text { High doses of } \alpha \text {-tocopherol and } \\
\text { ascorbate can delay the time of } \\
\text { administration of L-dopa in PD } \\
\text { patients }\end{array}$ & $\begin{array}{l}\text { The combination of these natural } \\
\text { antioxidants delayed by } 2.5 \text { years, the } \\
\text { time for the start of the } \\
\text { administration of L-dopa in PD } \\
\text { patients. }\end{array}$ & $\begin{array}{l}\text { Fahn S, } \\
1991\end{array}$ \\
\hline $\begin{array}{l}\text { Long-term supplementation with } \\
\text { vitamin E may provide cognitive } \\
\text { benefits. }\end{array}$ & $\begin{array}{l}\text { No differences were found between } \\
\text { groups treated with vitamin E and } \\
\text { placebo groups }\end{array}$ & $\begin{array}{l}\text { Jae Hee } \\
\text { Kang, } 2006\end{array}$ \\
\hline $\begin{array}{l}\text { The intake of high doses of } \\
\text { vitamin E (400-4000 IU / day) can } \\
\text { slow the progression of PD by } \\
\text { inhibiting nigral cell death }\end{array}$ & $\begin{array}{l}\text { No increased levels of vitamin E in } \\
\text { the cerebrospinal fluid of patients } \\
\text { with PD. However, the subjects had } \\
\text { clinical symptoms of the disease } \\
\text { when vitamin E was administered. }\end{array}$ & $\begin{array}{l}\text { Pappert, } \\
\text { E.J }\end{array}$ \\
\hline
\end{tabular}

Table 1. Vitamin E or Tocopherol starring in several studies evaluating the antioxidant supplementation and its effects on cognitive deficits related with ND 
the most active and widely distributed (Elejalde, 2001); it is found naturally in foods such as vegetable oils, fats, vegetables, egg yolks, nuts, seeds, fruits and green vegetables (Berman \& Brodaty, 2004). In addition to its antioxidant properties, also has capabilities such as specific enzymes regulating agent, anti-inflammatory and neuroprotective (Martin et al., 1999). Due to its neuroprotective properties, researchers worldwide have taken a particular interest in elucidating their protective mechanisms, as opposed to development of cognitive dysfunction related to aging and various ND (Table 1) (Ramesh et al, 2010).

The neuroprotective effect of vitamin $\mathrm{E}$ was first described in 1992 in an in vitro study using neuronal cells cultures (Behl C, et al, 1992). However, in order to know whether dietary supplementation with antioxidants can increase their brain levels, it is essential to investigate the effect of such molecules in animal models of ND like the EP (Prasad et al., 1999). In this regard, previous studies suggest that long-term feeding of rats (6 to 15 months of age) with a dietary supplement of $500 \mathrm{IU}$ of vitamin E, induces protective effects against cognitive deficit related to age (Morris et al., 2005; Peterson et al., 2005). Similarly, it has been reported that supplementation with vitamin $\mathrm{E}$ in combination with vitamin $\mathrm{C}$, increases the concentration of these vitamins in plasma and cerebrospinal fluid, where the resistance of lipoproteins to oxidation in in vitro studies is increased (Kontush et al, 2001; Casetta et al., 2005). It has also been reported that dietary supplementation with $\alpha$ tocopherol (1000 IU/day) for four months increases brain levels of vitamin $\mathrm{E}$ in rats (Vatassery et al., 1988), as in the brain and cerebrospinal fluid of dogs treated during two years (SR Pillai, 1993). These results suggest that dietary supplementation with vitamin E may be valuable in animal models of PD (Prasad et al., 1999).

On the other hand, one of the largest studies with antioxidants as a treatment for AD, included 341 patients with moderate dementia who were given 4 different treatments: $10 \mathrm{mg} /$ day of selegiline (a selective MAO inhibitor), 2000 IU daily $\alpha$-tocopherol, a combination of selegiline and-tocopherol, or placebo. The effect of the treatments was assessed through the presentation of clinical signs such as loss of ability to perform basic activities of daily living, severe dementia or death. After the treatments the authors observed a significant delay in the time of presentation of clinical signs in patients treated with selegiline, alpha-tocopherol, or in combination compared with placebo (Sano, 1996, 1997). However, there was no additive effect of selegiline and vitamin $E$, possibly due to a common mechanism of action in which lower levels of free radicals, and prevents its formation through inhibition of oxidative metabolism of catecholamines (Casetta et al., 2005). Similarly, studies by Behl, C., 2000, suggest a neuroprotective activity of both, the natural tocopherol and the synthetic. In addition, the effect appears to be superior to that described for estradiol (powerful antioxidant), in terms of the ability of neuronal protection against oxidative damage generated by $\beta$-amyloid protein in AD. Additionally, there are studies that seek to enhance the antioxidant effect of tocopherol, in combination with other vitamins such as Vitamin C. For example, in a prospective study in the Netherlands (Engelhart et al., 2002), they used a population of 5395 subjects at least 55 years, where the high intake of vitamin $\mathrm{C}$ and $\mathrm{E}$ was associated with a lower risk of developing $\mathrm{AD}$ after a follow up of 6.5 years. The relative risk was 0 . for vitamin $E$, and 0.82 for vitamin C (Casetta et al., 2005).

With respect to the source, the vitamin E supplements do not appear to offer better results than those obtained by eating foods rich in this vitamin (Kontush \& Schekatolina, 2004). This may be due to the cumulative and synergistic, as the bioavailability of vitamins is 
concerned. However, not be ruled out that the apparent protection provided by the supplementation of vitamins $\mathrm{E}$ and $\mathrm{C}$, is the result of the synergy of these vitamins and other substances in fruits and vegetables such as flavonoids, which have both antiinflammatory properties as antioxidants (Ramesh et al., 2010; Seshadri \& Wolf, 2003). It has also been suggested that vitamin $E$ supplements can reduce levels of $\beta$-amyloid in a transgenic model of AD. However, this effect was only observed in young mice but not in older animals. These results may suggest that antioxidant therapy may be beneficial only if given at an early stage of the disease (Sung et al., 2004; Casetta et al., 2005).

The inconsistencies found between the results of these and other studies of vitamin $E$, lead to consider that most supplements used are composed exclusively of $\alpha$-tocopherol, leaving aside the action of other forms of tocopherol that make this vitamin. Therefore, it has been suggested that the protective effect of vitamin $\mathrm{E}$ in the brain is the result of the combined intake of all forms of tocopherol (Farrell \& Roberts, 1994).

\subsubsection{Vitamin C}

Vitamin C or ascorbic acid is a soluble molecule that has a variety of functions, which include the recycling of oxidized forms of vitamin $\mathrm{E}$ and the activation of certain enzymes (McCay, 1985; Chan, 1993; Elejalde, 2001). Importantly, in vivo there are interactions between vitamin $\mathrm{E}$ and vitamin $\mathrm{C}$, where the role of antioxidant vitamin $\mathrm{E}$ has proven to be improved by supplementation of vitamin $C$. This interaction, however, involves the two vitamins, whose levels are not regulated by metabolism, but depend on consumption in the diet (Kagan, \& Tyurina, 1998). Humans and other primates are unable to synthesize this vitamin, while most mammals, including rats and mice produce the endogenous form of this molecule in the liver (Chatterjee et al., 1975).

Vitamin $C$ is found at high levels in a variety of cells, including neurons, where it participates in the biosynthesis of catecholamines and plays an important role as a cofactor of dopamine-hydroxylase. Vitamine $C$ and vitamin $E$ inhibit peroxidation of membrane phospholipids and act as free radicals scavenger (Gilgun-Sherki et al., 2001). Some authors report that ascorbic acid protects low density lipoprotein from oxidation and reduces oxidizing molecules that damage the integrity of the Central Nervous System (Sales et al., 2009). Given these properties, the scientific interest in this vitamin is to know about their effects on neuronal damage induced by agents such as pilocarpine, where has been found that antioxidant treatment significantly reduces the level of lipid peroxidation and nitrite content, and also potentiates the activity of SOD and CAT in the hippocampus of adult rats after pilocarpine-induced seizures. (Sales et al., 2009).

With respect to the ND, Hellenbrand et al., 1996, found that vitamin C has a protective effect against PD, with statistically significant trend. Several studies in populations aged 65 or older focused their interest on the combined effect of vitamin $C$ and other antioxidants such as vitamin E, beta-carotene, or flavonoids, and these could be associated with reduction of dementia / incidence of AD or reduction of cognitive decline (Esposito et al, 2002; Coley et al., 2008). Zandi et al., 2004 reported that using the combination of high doses of vitamins $E$ and $C$ are associated with reduced prevalence and incidence of $A D$, even, once initiated the disease.

\subsubsection{Vitamin B}

B complex vitamins such as thiamin (vitamin B1), lipoic acid, biotin, vitamin B6, folic acid, vitamin B12, pantothenate, symbiotically work together to boost the pyruvate dehydrogenase 
complex, and the contribution of gluconeogenesis oxygen to the brain. In addition, due to the critical role that these nutrients play in the metabolism of glucose and mitochondrial respiration justifies the use of B vitamins for patients with PD (Mazzio et al., 2011). Some authors argue that a relationship exists between the PD, vitamin B6, vitamin B12 and folic acid. This relationship refers to the role played by these molecules in the regulation of homocysteine, since they are responsible for their cleavage to methionine and tetrahydrofolate. Such effects may attenuate the neurotoxicity associated with a condition known as hyperhomocysteinemia, which is associated with PD and cytotoxicity related Mitochondrial Transitory Permeability Pore (Mazzio et al., 2011). Additionally, it has been suggested that elevated levels of homocysteine may increase the severity of PD, since this amino acid could mediate neuronal toxicity through NMDA receptors, precipitating oxidative stress, calcium overload and apoptosis (Mazzio et al., 2011). Homocysteine has also been associated with states of oxidative stress related with AD. In fact, there are some reports of an increased intake of vitamin B6 (Tucker et al., 2005; Corrada et al., 2005), vitamin B12 or folate (Wang et al., 2001; Morris et al., 2005), in middle-aged or advanced age people, with the belief of obtaining a beneficial effect on the incidence of AD or cognitive impairment (Coley et al, 2008).

In this regard, several studies seeking to assess the impact of high doses of vitamin supplements on plasma homocysteine levels in patients with AD (Aisen et al., 2003). For example, a study in patients with $\mathrm{AD}$ evaluated the effects of supplementation of these individuals over a period of 18 months. The results indicated that the groups treated with high doses of folic acid, vitamin B6 and B12 reduced by $20-30 \%$ peripheral levels of homocysteine, however, the study showed no cognitive differences between individuals treated with antioxidants and individuals treated with placebo (Aisen et al., 2003).

\subsection{Polyphenols}

As mentioned above, the use of vitamin supplements may promote the biological integrity of systems, however, the combined use of vitamins and plant-derived polyphenolic compounds, seems to have good recognition as antioxidants (Mazzio et al., 2011). The use of supplements from plants to improve health is an issue that is gaining popularity among most people because it is considered that the use of natural products is safe and produces fewer side effects, compared to synthetic drug, in fact, to date over 50 different species of plants, and more than 8000 phenolic compounds have been identified with beneficial effects on health (Sun et al., 2008).

Polyphenols can be divided into different groups depending on the number of rings of phenol and the chemical group attached to these rings. The most representative of this group of substances are the flavonoids, which are subdivided into flavonoids (catechin, epicatechin), flavonols (quercetin, myricetin, kaempferol), flavanones (hesperetin, naringenin), flavones (apigenin, luteolin), isoflavones (genistein, daidzein) and anthocyanins (cyanide, malvidin) (Ramassamy, 2006; Sun, et al., 2008). These molecules are found in a wide variety of food products from plants. One of the most important aspects of the polyphenols current research is their neuroprotective capacity. This section will define and describe in detail the neuroprotective mechanisms of these macromolecules, and also, will discuss recent evidence regarding their potentially antioxidant effect to prevent or to control the development of neuropathology as AD or PD. 


\subsubsection{Plant polyphenols}

Polyphenols are a class of phytoalexins found in a wide range of plants, fruits and vegetables (Bastianetto \& Quirion, 2002; Brannon et al., 2010; Ramassamy, 2006; Ramesh et al., 2010). When ingested they are transported from the circulatory system to various body organs including the brain (Sun et al., 2008). It has also been found to be potent recyclers of superoxide radicals, hydrogen peroxide and oxygen (Morel et al., 1993; Nanjo et al., 1996; Ramassamy, 2006), mechanisms that together with the anti-inflammatory activity have been extensively studied in order to know their beneficial effects against aging-related processes (Table 2) (Brannon \& Trygve, 2010; James et al., 2009).

The ability of polyphenols to act as antioxidants is given by its ability to chelate metal ions, which is achieved by suppressing reactive species that contribute to oxidative damage (Brannon \& Trygve, 2010). This antioxidant capacity depends on the molecular structure of each polyphenol, the position of hydroxyl groups, and other substitutions in their chemical structure (Sun et al., 2008). In addition to the antioxidant capacities, several polyphenols exhibit multiple biological properties among which are the anti-inflammatory, anticancer, antiviral, antimicrobial, vasodilator and anti-coagulant (Rahman et al., 2007). Additionally, in vitro studies demonstrate that polyphenols may possess the ability to activate or inhibit several signaling pathways such as NF-к $\beta$, SIRT1, MAPK's, heat shock proteins and other regulatory molecules, which may play an important role in basic functions such as senescence, apoptosis and the activation or production of transcription factors (Brannon \& Trygve, 2010).

Furthermore, polyphenols are natural antioxidants that after consumption tend to produce an increase in plasma antioxidant capacity, and also can inhibit the oxidation of low density

\begin{tabular}{|l|l|l|}
\hline Polyphenol & Effect & Result \\
\hline Resveratrol & $\begin{array}{l}\text { Activation of SIRT1 driving to } \\
\text { deacetylation of p53, NF- } \beta, \text { HSF-1, } \\
\text { FOXO1/3/4 y PGC-1 } \alpha . \\
\text { Activation of SIRT1 can mimic } \\
\text { caloric restriction } \\
\text { It binds to receptors in the brain to } \\
\text { stimulate the production of } \\
\text { transthyretin (TTR) }\end{array}$ & $\begin{array}{l}\text { Influence on senescence, } \\
\text { inflammation, apoptosis, resistance } \\
\text { to stress and metabolism } \\
\text { Increment of half life } \\
\text { TTR sequesters beta-amyloid fibrils }\end{array}$ \\
\hline EGCG & $\begin{array}{l}\text { Regulates NO production in } \\
\text { endothelial cells } \\
\text { Regulates NO production in } \\
\text { carcinoma cells } \\
\text { Blocks EGF receptor in cervical } \\
\text { cancer cells }\end{array}$ & $\begin{array}{l}\text { Prevents inflammation associated } \\
\text { with atherosclerosis } \\
\text { Prevention of metastasis }\end{array}$ \\
\hline Quercetine & $\begin{array}{l}\text { Regulates production of TNF- } \alpha \\
\text { Prenor growing }\end{array}$ \\
\hline
\end{tabular}

Table 2. Attenuation of diseases associated to aging by action de polyphenols (Brannon \& Trygve, 2010) 
lipoprotein. These features have drawn public attention, since several of these substances have therapeutic potential against diseases such as cancer, ischemia, heart, liver, and neurodegenerative diseases (Mandel et al., 2003). Thus, numerous studies in different models of neurodegeneration in vitro and in vivo have shown that polyphenols can prevent and/or reduce oxidative damage by free radicals generated (Mandel \& Youdim, 2004; Scalbert et al., 2005). Numerous epidemiological estudies have shown neuroprotective effects of polyphenols and have established a clear relationship between these effects and decreased risk of neurological dysfunction associated with aging (Mandel et al., 2003). However, the nature of these protective effects, is not limited to the antioxidant properties, since recent evidence derived from in vitro cellular models, suggest that polyphenols such as resveratrol and EGCG, besides having the ability to recycle free radicals directly, also may regulate the cytotoxic effects of oligomers of $\beta$ A via phosphorylation of phosphokinase $\mathrm{C}$. In addition, polyphenols such as EGCG and resveratrol possess the ability to activate the enzyme transmembrane $\alpha$-secretase, which catalyzes the formation of a soluble and amyloidogenic (no plaque-forming) from the amyloid precursor protein (APP). Through this pathway, APP is formed and therefore do not allow the formation of neuritic plaques, a hallmark of AD. This information indicates that polyphenols may be used in therapies to exert control over the APP related molecules, and may suggest avenues for the development of new treatments that reduce the risk of developing $\mathrm{AD}$ according to the aging process. (Brannon \& Trygve, 2010).

Additionally, studies such as James et al., 1999, showed the extracts of blueberry or strawberry (high in polyphenols) as substances that can significantly attenuate cognitive and motor deficits related to aging in rodents. In this study, rodents of all treatments showed improvement in short-term memory according to the Morris water test. However, while these diets were supplemented based on an equal antioxidant capacity (determined by absorbance capacity test the oxygen radical, ORAC) was not found equal effectiveness in the prevention or reversal of the changes associated with aging. Additionally, the antioxidant capacity alone was not predictive in evaluating the potential of these compounds against certain age-related disorders. In fact, markers of oxidative stress (DCF fluorescence, and glutathione peroxidase level in the brain) were slightly reduced by the diets, suggesting that the polyphenols from berries can have multiple actions in addition to the antioxidant.

Other possible mechanisms for the beneficial effects of these foods are: direct effects on signaling to enhance neuronal communication, the ability to act as a buffer against excess calcium, enhancement of neuroprotective proteins and reduction of signs of stress such as NF $-\kappa \beta$. (Calabrese et al., 2010). According to studies in cell cultures and animal models, there is a cascade of signaling between the molecules and effects of eating berries. For example, treatment with berries to COS-7 cells exposed to dopamine or to hippocampal primary neurons, significantly increased the expression of MAPK mitogen. Additionally, mice supplemented with berries APP/PS1, exhibited high levels of hippocampal extracellular signaling regulated by ERK, such as protein kinase $C$ (PKC) $\alpha$, compared with transgenic mice maintained on control diets. In addition, Brannon \& Trygve, 2010, suggests that treatment with berries is effective protection against the toxic effect of $\beta \mathrm{A}$ and against the decline in the induction of dopamine in the regulation of intracellular calcium in COS-7 cells transfected hippocampal neurons. This protection suggests an increase in phosphorylated MAPK and decreased PKC $\gamma$. 


\subsubsection{Epigallocatechin 3-Gallate (EGCG)}

EGCG is a polyphenol flavonoid type found in large quantities in green tea. According to some authors, this compound has exerts significant neuroprotective effects against a wide range of oxidative insults in a multitude of neuronal cell models (Calabrese et al., 2010; Kelsey et al., 2010). In one study, CGNs incubated cells with an inhibitor of Bcl-2 known as HA14-1, which generates oxidation and mitochondrial intrinsic apoptosis (Zimmermann et al., 2007), applying the co-treatment with EGCG, was found that the microtubule network of CGNs exposed to HA14-1 was significantly preserved, and so, was prevented the apoptotic nuclear morphology (Kelsey et al., 2010). In fact, studies like that of Weinreb et al., 2004, showed that treatment of neuronal cells with EGCG affects the expression levels of various proteins, including proteins related to components of the cytoskeleton, metabolism, and binding proteins (Calabrese et al., 2010; Izumi et al., 2005). EGCG similarly protects human neuroblastoma cells (SH-SY5Y) against the cytotoxicity associated with the amyloid precursor protein (APP), and the 6-hydroxydopamine (6-OHDA) (Avramovich et al., 2007), thus, rescues PC12 cells from serum deprivation-induced apoptosis or paraquat (Hou et al., 2008; Kelsey et al., 2010; Mandel et al., 2003). Also, supplementation of transgenic mice over expressing APP (APPsw) substantially reduced amyloid plaque burden and reduced cognitive impairment (Rezai-Zadeh et al., 2005, Kelsey et al., 2010). Similarly, in murine N2A cells transfected with a mutant form of human APP (Rezai-Zadeh et al., 2005) was found that EGCG reduced the generation of $\beta$-amyloid (Ramassamy, 2006).

In addition to the neuroprotective effects of EGCG observed in in vitro studies, this antioxidant also preserved neuronal survival and function in several in vivo models of neurodegeneration. For example, supplementation to mice with EGCG protected dopaminergic neurons in the substantia nigra pars compacta from toxicity induced MPTP, therefore it could preserve the levels of dopamine in the striatum (Levites et al., 2001). Similarly, the acute and chronic administration of EGCG has been evaluated in various cell and animal models of $\mathrm{AD}$, where it has been suggested that EGCG significantly reduced the toxicity induced by $\beta$-amyloid (Kelsey et al., 2010). With respect to PD, Sung et al, 2010, used models in vitro and in vivo to investigate the modulation of the effects of EGCG on L-dopa and induced neuronal damage. The results indicated that oral supplementation with this antioxidant initiated potential beneficial effects in patients with PD treated with L-dopa as moderately inhibits methylation of this molecule. Similarly, Levitas et al., 2001, using mice as animal model of PD which were given a pre-treatment with green tea extract $(0.5$ and 1 $\mathrm{mg} / \mathrm{kg}$ ) or EGCG (2 and $10 \mathrm{mg} / \mathrm{kg}$ ) prevented the damage generated by the neurotoxin (MPTP) on dopaminergic neurons in the nigrostriatal pathway.

Another type of molecular mechanism involved in neuroprotection by EGCG is mediated gene activation in apoptosis. Evidence of this assertion is found in studies such as that by Levites et al., 2002, which results in neuroblastoma cells SH-SY5Y showed that EGCG decreased the gene expression of pro-apoptotic such as Bax, Bad, Fas ligand and TRAIL (tumor necrosis factor-related apoptosis-inducingligand), however, the expression of Bcl-2 and Bcl-x was not affected (Levites et al., 2002). These results suggest that the neuroprotective effects of EGCG may involve the inactivation of proapoptotic genes, rather than the action of anti-apoptotic mitochondrial proteins (Ramassamy, 2006). Taken together, these findings indicate that EGCG may be a therapeutic candidate for chronic neurodegenerative diseases like AD and PD (Weinreb et al.,2004; Frank \& Gupta, 2005), and may be beneficial in acute episodes of neuronal damage, such as spinal cord trauma. 


\subsubsection{Quercetin}

Quercetin is a flavonoid found in different types of food such as apples, capers, onions, broccoli, tea and wine (Boots et al., 2008; Esposito et al., 2002; Kelsey et al, 2010). As EGCG, quercetin has been widely studied in in vitro and in vivo assays in neural models (Ossola et al., 2009). Thus, PC12 cell studies showed that quercetin enhances cell survival in the presence of hydrogen peroxide (Dajas et al., 2003; Heo \& Lee, 2004), linoleic acid (Sasaki, et al., 2003), and tert-butyl (Silva et al., 2008). Furthermore, in human neuroblastoma cells SHSY5Y used as experimental models for PD, this substance has shown to have protective ability against toxicity by 6-OHDA (Kelsey et al., 2010). Also, other study about neurodegeneration in animal models have suggested that the neuroprotective capacity of quercetin could be related to increased blood-brain barrier permeability, thus facilitating the penetration of the substance in the brain (Ossola et al., 2009).

Taken together, these studies indicate that quercetin has the potential, such as EGCG, to block the starting of the enzymatic oxidation of dopamine (Tamura et al., 1994), and this could means a new therapy against neurodegenerative diseases such as PD (Kelsey et al., 2010). However, Ossola, et al., 2009 states that despite the fact that quercetin has not shown significant toxicity in several animal studies, the risk of neurotoxicity is not negligible due to its narrow therapeutic dose range in in vitro experiments, also the effectiveness of quercetin in ND is quite low.

\subsubsection{Resveratrol}

Resveratrol (trans-3, 4 ',5-trihydroxystilbene) is a polyphenol found abundantly in grapes and red wine, it is known for its antioxidant and neuroprotective properties in several experiments, therefore, consumption of wine has been proposed as a possible benefit in neurodegenerative processes (Calabrese et al., 2010; Esposito et al., 2002; Kiziltepe et al., 2004; Ramasamy, 2006). The main biological activities attributed to resveratrol include: inhibition of lipid peroxidation and free radicals in cell cultures and rat brains (Virgili \& Contestabile, 2000, Casetta et al., 2005), vasodilator, anti-inflammatory and anticancer. Also, It has been shown that mice fed with daily dose of resveratrol for 45 days, had resveratrol or its metabolites in the brain, indicating its bioavailability to neuronal cells (Casseta et al., 2005; Contestabile, 2001; Karuppagounder et al., 2008; Ramesh et al., 2010).

In the field of ND has been suggested that resveratrol not only attenuated the cytotoxicity induced by $\beta$-amyloid, but also blocks the accumulation of intracellular reactive oxygen species typical of apoptosis (Casetta et al., 2005; Jang \& Surh, 2003). In addition, partial neuroprotection was demonstrated in rats with chronic supplementation of resveratrol in in vivo studies of excitotoxicity related to the administration of agonists for glutamate and kainic acid receptors, (Contestabille, 2001; Virgili \& Contestabile, 2000). The consumption of about $8 \mathrm{mg} / \mathrm{kg} /$ day of resveratrol for 45 days decreased excitotoxic damage measured on the basis of the reduction of certain neuromarcador of GABAergic neurons, from $38 \%$ to $14 \%$ in the olfactory cortex and $27 \%$ to $12 \%$ in the hippocampus. This was the first report of neuroprotection by long-term administration of resveratrol in an in vivo model of neurodegeneration (Contestabille, 2001). Similarly, Han, 2003, showed that cell death induced by administration of $\beta$-amyloid peptide $(20 \mu \mathrm{M})$, decreased significantly, and protein concentration-dependent by treatment with resveratrol administered 2 hours later. Also, in two different transfected cell lines (HEK293 and N2A), Marambaud et al., 2005, showed that resveratrol may reduce the secretion of $\beta$-amyloid peptide, perhaps through the activation of proteosomal degradation of the peptide. This effect of resveratrol occurred 
without the direct involvement of the $\beta$ and $\gamma$-secretase, but, Brannon \& Trygve, 2010, argues that resveratrol can activate transmembrane protein $\alpha$-secretase. However, it is still unclear the effect of resveratrol on the mechanism of degradation of $\beta$-amyloid levels in neurons, although it is suggested that may have a key effect on the route of clearance of beta-amyloid (Marambaud et al., 2005; Ramesh et al., 2010).

With respect to cell signaling pathways related to the effects of resveratrol has been shown that its protective activity is related to the PCK phosphorylation, leading to its activation, and the activation of no amyloidogenic cleavage pathways of APP, decreasing the release of $\beta$-amyloid (Han, 2003; Ramesh et al., 2010). Similarly, studies in neuroblastoma cells SHSY5Y by Miloso et al.,1999, argue that resveratrol can induce activation of MAP kinases ERK1 and ERK2. In addition to these signaling pathways, resveratrol can also induce the expression of the response of the transcription early growth factor (Egr1) (Della Ragione et al., 2002), which could regulate some aspects of synaptic plasticity related to learning and memory (Li et al., 2005). Additionally, resveratrol may interact with other proteins, including members of the sirtuins family. Deacetylases sirtuins are related to mechanisms of cellular longevity (Guarente, 2001), resveratrol acts as a potent activator of these molecules, thus related to neuroprotective pathways (Araki et al., 2004; Ramesh et al., 2010). Other intracellular signaling mechanisms that may be implicated with the neuroprotective effect of resveratrol against $\beta$-amyloid peptide include the modulation of NF-kB pathways or NF$\mathrm{kB} / \mathrm{SIRT1}$, where resveratrol can inhibit the activity of NF-kB induced $\beta$-amyloid peptide through the activation of SIRT1 (Ramassamy, 2006).

With respect to the high amounts of resveratrol contained in red wine, investigations that assess moderate alcohol consumption show that this practice was significantly associated with lower risk of acquiring dementia and $\mathrm{AD}$, compared to non-consumption (Casseta et al., 2005). Similarly, several epidemiological studies indicate that moderate wine consumption may be associated with a lower incidence of AD (Lindsay et al., 2002; Orgogozo et al., 1997; Truelsen et al., 2002), and additionally, different studies in vitro and in vivo have investigated the basis for this association. For example, doses from 10 microM of resveratrol in PC12 cells have demonstrated protective ability against the cytotoxicity induced by amyloid $\beta$ (Jang \& Surh, 2003). It has also been reported that the combination of resveratrol with other flavonoids such as catechin, may exert synergistic protection against the toxicity of amyloid $\beta$ peptide in PC12 cells (Conte et al., 2003). However, there has not been demonstrated the relevance of these findings in vivo models (Ramassamy et al., 2010). Moreover, it is difficult to reconcile the therapeutic potential of resveratrol with the well known toxic effects of ethanol (Calabrese et al., 2010), because it does not seem reasonable to recommend alcohol consumption to those with tendency to addiction (Ramesh et al, 2010; Resnick \& Junlapeeya, 2004).

\subsubsection{Ginkgo biloba}

The extract of Ginkgo biloba EGb 761 is a substance from the green leaves of Ginkgo biloba (Drieu, 1986). This extract was patented in 1990 and has a wide range of biochemical and pharmacological activities, including the antioxidant activity (Marcocci et al., 1994), the neurotrophic capacity in the hippocampal formation (Barkats et al., 1995; Bastianetto \& Quirion, 2002), and the neuroprotective ability against neurotoxicity induced by $\beta$-amyloid peptide (Casseta, et al., 2005; Luo et al., 2002; Yao et al., 2001;).

The therapeutic use of Ginkgo biloba has been proposed due to its high content of flavonoids and terpenoids, and is widely used in Europe to alleviate symptoms associated 
with the progression of cognitive impairment, in fact, several studies argue that extracts of Ginkgo biloba may be effective in delaying the clinical deterioration of patients with dementia (Ernst \& Pittler, 1999; Casseta et al., 2005). The effects of EGb 761 may be explained, at least in part, based on their protective actions in animal models of hypoxia and ischemia (Droy-Lefaix et al., 1995) and in vitro models of toxicity (Ni et al., 1996; Oyama et al., 1996; Xin et al., 2000), also a prospective placebo-controlled study demonstrated the therapeutic efficacy of oral administration of EGb 761 in dementia patients and healthy adults showed improved memory and attention (Bastianetto \& Quirion, 2002; Maurer et al., 1997; Mix et al., 2000). A case-control study that used a cohort of 1,462 women aged 75 years was conducted to test the effectiveness of the prevention of $\mathrm{AD}$ using EGb761, the conclusion is that the small number of women who developed dementia were prescribed with the supplement at least for two years. These results suggest that EGb 761 treatment may reduce the risk of developing Alzheimer's dementia in older women (Andrieu et al, 2003; Casseta, et al., 2005).

Additionally, Bastianetto \& Quirion, in 2002, conducted a study in vitro with embryonic mouse hippocampal cells on which were used two different protocols of citotoxididad, one with $\beta$-amyloid (A_25-35 (25_M) A_1-40 (5_M) A_1-42 or (25_M)), and the other with sodium nitroprusside (SNP) to assess whether the components of red wine were able to reduce cell death caused by $\beta$-amyloid and oxidative stress. We found that EGb 761, possibly through the antioxidant properties of its flavonoids was able to protect hippocampal cells against the toxic effects previously described.

The mechanisms of action underlying the protective effects of EGb 761, have been evaluated in different studies. For example Bastianetto\& Quirion, in 2002, noted in his study that the treatment with EGb 761 were able to inhibit the injury induced by $\beta$ A 25-35, and NO. In addition, the extract showed protective effect against the harmful effects of $\mathrm{H} 2 \mathrm{O} 2$, a supposed mediator of the toxicity caused by $\beta$-amyloid (Behl et al., 1994). These data suggest that the scavenging properties of hydroxyl radical of the EGb 761, may be part of the protection against $\beta$-amyloid toxicity (Oyama et al., 1996; Bastianetto \& Quirion, 2002). Finally, it has been reported that EGb 761 inhibits a number of apoptotic events induced by $\beta \mathrm{A} 25-35$, a process that may be relevant to the neuro-degeneration that occurs in $\mathrm{AD}$ (Johnson, 1994). In addition, these anti-apoptotic effects of EGb 761 are apparently related to the ability to inhibit the toxicity induced by $\mathrm{H} 2 \mathrm{O} 2$, and that this natural extract has been reported as an effective tool to the apoptosis hydroxyl radical-induced in cultured neurons (Bastianetto \& Quirion, 2002; Ni et al., 1996, Xin et al., 2000).

\subsubsection{Curcuminoides}

The curcuminoids are the active component of turmeric, which have been attributed to have capacity as an inhibitor of lipid peroxidation, and free radical scavenger, it is a potent antiinflammatory and anticancer, and is also traditionally used in Asia (Aggarwal et al., 2007; James, et al., 2009; Ramesh et al., 2010). In light of its antioxidant, anti-inflammatory and anti-amyloid actions, curcumin is being investigated as a candidate compound for the prevention or treatment of diseases such as multiple myeloma, pancreatic cancer, myelodysplastic syndromes, colon cancer, psoriasis and AD (Calabrese et al., 2010; Goel, et al., 2008).

The curcumin reduces pro-inflammatory cytokines, oxidative damage, the A $\beta 42$ and cognitive deficits in models of AD (Frautschy et al., 2001). Also, has been told that it is a direct inhibitor of $\beta \mathrm{A}$ aggregation and fibril formation (Cole et al., 2003; James et al., 2009). 
Similarly, curcumin has anti-AD activities, including, limitation of the kinase JNK (c-Jun Nterminal protein kinase) and stimulation of neurogenesis (Cole et al., 2007; James et al., 2009). Moreover, previous research has shown that turmeric reduces inflammation and oxidative damage in Tg2576 transgenic mouse brain A 3 PPSw (Kumar \& Singh, 2008; Lim et al., 2001,), and that curcumin reduces the level of soluble and insoluble $\beta A$ in several brain regions. Therefore, it has been suggested that this substance could prevent the onset of AD, not only by scavenging reactive oxygen species, but also by inhibiting the aggregation of $\beta \mathrm{A}$ in the brain (Ramesh et al., 2010). Similarly, Lim et al., 2001, studied the effects of the curcumin in transgenic mice carrying a human mutation of the amyloid precursor protein (APPsw) that causes AD (Lim et al., 2001) and found a reduction in brain level of oxidized proteins, and a decrease in both the level of soluble and insoluble $\beta A$, and the plaque burden (Lim et al., 2001). However, more studies are needed to test the potential therapeutic use of curcumin for the treatment or prevention of AD in humans (Calabrese et al., 2010).

The benefits of curcumin derive from its complex chemical structure and its ability to influence multiple signaling pathways, for instance, survival pathways such as those regulated by NF-kB, the Nrf2-dependent cytoprotective pathways, and routes of metastasis and angiogenesis (Calabrese et al., 2010; Goel et al.,2008; Ramsewak et al., 2000).

Because curcumin is highly toxic and has a limited bioavailability, the assessment of their impact on clinical practice has not been easy, however, using lipid formulations, this obstacle has been largely mitigated (Begum et al., 2008; James et al., 2009; Calabrese et al., 2010).

\section{Dietary recommendations for patients with ND as AD and PD}

Some evidence suggest that high intake of dietary antioxidants or fruits and vegetables provides nutritional compounds with antioxidant properties that may contribute to improving the quality of life, due to the decreased risk of degenerative diseases associated with aging and the accumulation of free radicals (Meydani et al.,1998). Therefore, although it is important to consider that dietary supplementation with $\mathrm{AO}$ may enhance cognitive longevity, and to some extent, reduces the risk of developing these diseases, it is also important to do some additional considerations. For example, the use of a single antioxidant, is not the best option, since the oxidation of individual antioxidants may promote oxidative stress, therefore, we recommend using combinations of antioxidants at the appropriate doses. Also, as mentioned previously, it has been found that diets rich in vitamin $\mathrm{E}$ may reduce the risk of $\mathrm{EP}$, and has also been suggested that moderate wine consumption may reduce the risk to suffer from AD. However, there is still controversy about the epidemiological data related to these hypotheses, which could be due partially to the intrinsic difficulties of epidemiological surveys on the eating habits in large populations (Esposito, et al., 2002).

However, nutritional factors remain a very relevant topic when setting up a comprehensive treatment in patients with dementia. In addition, the formulation of a specific diet for people with $\mathrm{AD}$ or $\mathrm{PD}$, requires a prior careful review of the patient, in order to identify their nutritional deficiencies, and thus design a healthy diet to ensure good physical health. For example, certain vitamins such as B12 and folic acid must be replaced to ensure that AD dementia is not due in part to this deficiency (Ramesh et al, 2010).

Finally, some authors argue that there is a lack of knowledge on these issues among medical professionals and clinicians, so they overlooked some dietary recommendations that could 
be used in conjunction with the approach of Neurogerontology (James et al, 2009), so, it is necessary to continue investigating the potential benefits of various $\mathrm{AO}$ against the prevention and/or treatment of ND as AD and PD.

\section{Conclusions}

As described earlier in this chapter, a variety of scientific evidence that describes the importance of different oxidative mechanisms which are part of the dynamic biological relevance of the ND as AD, PD or the CDS. Such approaches have led to a series of theories on the therapeutic use of antioxidants to slow down the chain reaction of oxidative events and thus to reduce its cytotoxic effects. Thus, consumption of antioxidants such as vitamin $E$ and $\mathrm{C}$, polyphenols and other antioxidants has became very important because they provide a series of defense mechanisms that promote longevity, reduce the risk of developing certain neuropathologies, and also can be consumed in a daily diet.

However, there are some data that are incompatible with these theories, leading to various disputes regarding antioxidant supplementation and its possible beneficial effects on the body. In this sense, it is important to consider factors that may limit somewhat the research in this field. Among these factors: choosing an appropriate dose, long-term monitoring of a large cohort study, the inclusion or exclusion of different environmental factors, and in vivo application of the results obtained in in vitro studies.

Occasionally, the start of antioxidant therapy for ND, is given when there may be a significant number of injured neurons, giving rise to specific clinical symptoms. In this case, antioxidants act on viable neurons, but do not recover the population of dead neurons. Therefore, in several studies of neuroprotection, supplying long-term supplements at the onset of the disease or even earlier is recommended; these results provide a valid evidence of the therapeutic effects of these substances and are a guarantee of further trials.

\section{References}

Aisen P.S., Egelko S., Andrews H., Diaz-Arrastia R., Weiner, M. DeCarli, C., Jagust, W.; Miller, J.W.; Green, R K. Bell \& Sano, M. (2003). A pilot study of vitamins to lower plasma homocysteine levels in Alzheimer disease, Am J Geriatr Psychiatry, Vol.11, pp.246-249.

Aggarwal BB, Sundaram C, Malani N, Ichikawa H (2007). Curcumin: the Indian solid gold. Adv Exp Med Biol, Vol.595, pp.1-75.

Andrieu S, Gillette S, Amouyal K, Nourhashemi F, Reynish E, Ousset PJ, et al. (2003). EPIDOS study. Association of Alzheimer's disease onset with ginkgo biloba and other symptomatic cognitive treatments in a population of women aged 75 years and older from the EPIDOS study. J Gerontol A Biol Sci Med Sci, Vol.58, pp. 372-7.

Araki T, Sasaki Y, Milbrandt J. (2004). Increased nuclear NAD biosynthesis and SIRT1 activation prevent axonal degeneration. Science, Vol.13, pp.1010-1013.

Araujo, J.A.; Studzinski, C.M. \& Milgram, N.W. (2005). Further evidence for the cholinergic hypothesis of aging and dementia from the canine model of aging. Prog. Neuropsychopharm. Biol. Psychiat, Vol.29, pp.411-422.

Avramovich-Tirosh, Y.; Reznichenko, L.; Mit, T.; Zheng, H.; Fridkin, M.; Weinreb, O.; Mandel, S. \& Youdim, M.B. (2007). Neurorescue activity, APP regulation and amyloid-beta peptide reduction by novel multi-functional brain permeable iron- 
chelating- antioxidants, M-30 and green tea polyphenol, EGCG. Curr. Alzheimer. Res, Vol.4, pp. 403-411.

Barkats M, Venault P, Christen Y, Cohen-Salmon C. (1995). Effect of longterm treatment with EGb 761 on age-dependent structural changes in the hippocampi of three inbred mouse strains. Life Sci, Vol.121, pp. 213-222.

Bastianetto, S. \& Quirion, R. (2002). Natural extracts as possible protective agents of brain aging. Neurobiology of Aging, Vol.23, pp.891-897.

Begum AN, Jones MR, Lim GP, Morihara T, Kim P, Heath DD, Rock CL, Pruitt MA, Yang F, Hudspeth B, Hu S, Faull KF, Teter B, Cole GM, Frautschy SA (2008). Curcumin structure-function, bioavailability, and efficacy in models of neuroinflammation and Alzheimer's disease. J Pharmacol Exp Ther, Vol.326, pp.196 -208.

Behl, C.; Davis, J.B.; Cole, G.M. \& Schubert, D. (1992). Vitamin E protects nerve cells from amyloid_protein toxicity. Biochem Biophys Res Commun, Vol.186, pp.944-50

Behl, C.; Davis, J.B.; Lesley, R. \& Schubert, D. (1994). Hydrogen peroxide mediates amyloid b protein toxicity. Cell, Vol.77, No.6, pp817-827, ISSN: 0092-8674.

Behl, C. (2000). Vitamin E protects neurons against oxidative cell death in vitro more effectively than 17-beta estradiol and induces the activity of the transcription factor NF-kappaB. J Neural Transm, Vol.107, No.4, pp. 393-407.

Benedetti, A.; Ferretti, G.; Curatola, G.; Jezequel, A.M. \& Orlandi, F. (1988). Age and sex related changes of plasma membrane fluidity in isolated rat hepatocytes. Biochemical and Biophysical Research Communications, Vol.156, No2, pp. 840-845, ISSN 0006-291X.

Berman, K. \& Brodaty, H. (2004). Tocopherol (Vitamin E) in Alzheimer's Disease and Other Neurodegenerative Disorders. CNS Drugs, Vol.18, No.12, pp. 807-825.

Birkmayer, W.; Birkmayer, J.; Vrecko, C.; Paletta, B.; Reschenhofer, E. \& Ott, E. (1990). Nicotnamide adenine dinucleotide (NADH) as medication for Parkinson's disease: Experience with 415 patients. Trends Clin Neuropharmacol , Vol.4, pp.7-24.

Boots, A.; Haenen, G. \& Bast, A. (2008). Health effects of quercetin: from antioxidant to nutraceutical. European Journal of Pharmacology, Vol.585, No.2-3, pp. 325-337, ISSN 0014-2999.

Braak, H. \& Braak, E. (1991). Neuropathological stageing of Alzheimer-related changes. Acta Neuropathologica, Vol.82, No.4, pp. 239-259, ISSN 0001-6322.

Brannon, L. \& Trygve O. (2010). Polyphenols and Aging. Curr Aging Sci, Vol.3, No.1, pp.3442.

Burton, G.W. \& Ingold, K.U. (1989) Vitamin E as an in vitro and in vivo antioxidant. Annals of the New York Academy of Sciences, Vol. 570, pp.7-22, ISSN 1749-6632.

Burton, G.W. \& Ingold, K.U. (1990). Mechanisms of antioxidant action: preventive and chain-breaking antioxidants. In: CRC Handbook of Free Radicals and Antioxidants in Biomedicin, Miguel, A., Quintanilha, A.T., Weber, H. (Eds.). Vol. II, CRC Press Inc. Boca Raton, FL. pp 29-43.

Butterfield, D.A.; Castegna, A; Lauderback, C.M. \& Drake, J. (2002) Evidence that amyloid beta-peptide induced lipid peroxidation and its sequelae in Alzheimer's disease brain contribute to neuronal death. Neurobiology of Aging, Vol.23, No.5, pp.655-664, ISSN 0197-4580.

Cadenas, E. (1997). Basic mechanism of antioxidant activity. Biofactors, Vol.6, No.4, pp.391397, ISSN 1872-8081 
Calabrese, V.; Calvani, M. \& Butterfield, D.A. (2006). Acetyl-L-carnitineinduced up-regulation of heat shock proteins protects cortical neurons against amyloid-beta peptide 1-42mediated oxidative stress and neurotoxicity: implications for Alzheimer's disease. $J$ Neurosci Res, Vol.84, pp. 398-408.

Calabrese, V.; Cornelius, C.; Trovato-Salinaro, A.; Cambria, M.T.; Locascio, M.S.; Di Rienzo, L.; Condorelli. D.F.; Mancuso, C.; De Lorenzo, A. \& Calabrese, E.J. (2010). The Hormetic Role of Dietary Antioxidants in Free Radical-Related Diseases. Current Pharmaceutical Design, Vol.16, pp.877-883.

Casetta, I.; Govoni, V. \& Granieri, E. (2005). Oxidative Stress, Antioxidants and Neurodegenerative Diseases. Current Pharmaceutical Design, Vol.11, pp. 2033-2052, ISSN 1381-6128.

Chan, A.C. (1993). Partners in defense. Vitamin E and vitamin C. Canadian Journal of Physiology and Pharmacology, Vol.71, No.9, pp.725-731

Chan, P.H. Reactive oxygen radicals in signaling and damage in the ischemic brain. (2001). Journal of Cerebral Blood Flow \& Metabolism, Vol. 21, No.1, pp.2-14, ISSN 0271-678X.

Chance, B.; Sies, H. \& Boveris, A. (1979) Hydroperoxide metabolism in mammalian organs. Physiological. Reviews, Vol. 59, No.3, pp. 527-605, ISNN 0031-9333.

Chatterjee, I.B., Majunder, A.L., Nandi, B.K., Subramanian, N. (1975). Synthesis and some major functions of vitamin C in animals. Annals of the New York Academy of Sciences, Vol.258, pp.24-47.

Chen, R.S.; Huang, C.C. \& Chu, N.S. (1997). Coenzyme Q10 treatment in mitochondrial encephalomyopathies. Short-term double-blind, crossover study. Eur Neurol, Vol.37, pp.212-218.

Cole G, Yang F, Lim G, Cummings J, Masterman D, Frautschy S (2003). A rationale for curcuminoids for the prevention or treatment of Alzheimer's disease. Curr Med Chem Immun Endoc Metab Agents, Vol.3, pp.15-25.

Cole GM, Teter B, Frautschy SA. (2007) Neuroprotective effects of curcumin.Adv Exp Med Biol, Vol.595, pp.197-212.

Coley, N.; Andrieu1, S.; Gardette, V.; Gillette-Guyonnet, S.; Sanz, C.; Vellas, B. \& Grand, A. (2008). Dementia Prevention: ethodological Explanations for Inconsistent Results. Epidemiol Rev, Vol.30, pp.35-66.

Conte, A., Pellegrini, S. \& Tagliazucchi, D. (2003). Synergistic protection of PC12 cells from beta-amyloid toxicity by resveratrol and catechin. Brain Res. Bull, Vol.62, pp.29-38.

Contestabile, A. (2001). Oxidative Stress in Neurodegeneration: Mechanisms and Therapeutic Perspectives. Current Topics in Medicinal Chemistry, Vol.1, No.6, pp.553568, ISNN 1862-2461.

Corrada M, Kawas C, Hallfrisch J, et al. (2005). Reduced risk of Alzheimer's disease with high folate intake: the Baltimore Longitudinal Study of Aging. Alzheimers Dement, Vol.1, pp.11-18.

Cotman, C.W.; Head, E.; Muggenburg, B.A.; Zicker, S. \& Milgram, N.W. (2002). Brain aging in the canine: a diet enriched in antioxidants reduces cognitive dysfunction. Neurobiology Aging, Vol.23, No.5, pp.809-18.

Cui, K.; Luo, X.; Xu, K. \& Ven, M.R. (2004). Role of oxidative stress in neurodegeneration: recent dvelopments in assay methods for oxidative stress and nutraceutical antioxidants. Progress in Neuro-Psychopharmacology \& Biological Psychiatry, Vol. 28, No.5, pp. 771- 799, ISSN 0278-5846. 
Dajas, F.; Rivera, F.; Blasina, F.; Arredondo, F.; Echeverry, C.; Lafon, L.; Morquio, A. \& Heizen, H. (2003). Cell culture protection and in vivo neuroprotective capacity of flavonoids. Neurotox. Res, Vol.5, pp. 425-432.

Dawson, T.M. \& Dawson, V.L. (1996). Free radical and neuronal cell death. Cell Death \& Differentiation, Vol.3, No1, pp. 71-78, ISNN 1350-9047.

Della Ragione, F., Cucciolla, V., Criniti, V., Indaco, S., Borriello, A., Zappia, V. (2002). Antioxidants induce different phenotypes by a distinct modulation of signal transduction. FEBS Lett, Vol.532, pp. 289-294.

Dreosti, I.; Meydani, M. \& Joseph, J. (1998). Annals of the New York Academy of Sciences (1998, 854:463-76).

Drieu, K. (1986). Preparation and definition of G. biloba extract. Press Med, Vol.15, pp.1455-7.

Droy-Lefaix MT, Menerath JM, Szabo-Tosaki E, Guillaumin D, Doly M. (1995). Protective effect of EGb 761 on ischemia-reperfusion damage in the rat retina. Transplantation Proc, Vol.27, pp.2861-2862.

Elejalde, R. (2001). Estrés oxidativo, enfermedades y tratamientos antioxidantes. Ann. Med. Interna, Vol.18, No. 6, pp. 326-335.

Ernst E \& Pittler MH. (1999). Ginkgo Biloba for dementia: a systematic review of doubleblind placebo-controlled trials. Clinical Drug Investigation, Vol.17, pp. 301-308.

Engelhart M.J., Geerlings MI, Ruitenberg A, van Swieten JC, Hofman A, Witteman JC, et al.(2002). Dietary intake of antioxidants and risk of Alzheimer disease. JAMA, Vol. 287, pp.3223-3229.

Esposito, E.; Rotilio, D.; Di Matteo, V.; Di Giulio, C.; Cacchio, C. \& Algeri, S. (2002). A review of specific dietary antioxidants and the effects on biochemical mechanisms related to neurodegenerative processes. Neurobiology of Aging Vol.23, pp. 719-735.

Fahn, S. (1991) An open trial of high-dosage antioxidants in early Parkinson's disease. American Journal of Clinical Nutrition, Vol.53 pp.380-382.

Fang, Y.; Yanq, S. \& Wu, G. (2002) Free radicals, antioxidants, and nutrition. Nutrition, Vol.18, No.10, pp. 872- 879, ISSN 0899-9007.

Farrell, P.M. \& Roberts, R.J. (1994) Vitamin E. In: Modern nutrition in health and disease, Shils ME, Olson JA, Shike M, eds, pp.326-341. Philadelphia.

Floyd, R.A \& Carney, J.M. (1992) Free radical damage to protein and DNA: Mechanism involved and relevant observations on brain undergoing oxidative stress. Annals of Neurology, Vol.32, Suppl.S22-27

Frank, B. \& Gupta, S. (2005). A review of antioxidants and Alzheimer's disease. Ann. Clin. Psychiatry, Vol.17, pp. 269-286.

Frautschy SA, Hu W, Kim P, Miller SA, Chu T, Harris-White ME, Cole GM (2001) Phenolic anti-inflammatory antioxidant reversal of Abetainduced cognitive deficits and neuropathology. Neurobiol Aging, Vol.22, pp.993-1005.

Frei, B., Stocker, R., Ames, B.N., (1988). Antioxidant defenses and lipid peroxidation in human blood plasma. National Academy of Sciences of the United States of America, Vol. 85, No.24, pp. 9748- 9752, ISSN 0027-8424.

Freidovich, I. (1999). Fundamental aspects of reactive oxygen species, or what's the matter with oxygen? Annals of the New York Academy of Sciences, Vol.893, No.1, pp. 13-18, ISSN 0077-8923.

Gallego, D.Y; Figueroa, J. \& Orozco, C.A. (2010a). Síndrome de disfunción cognitiva del perro como modelo de investigación de las enfermedades neurodegenerativas del humano. Revista de la Facultad de Medicina, Vol.58, No.2, pp.142-154, ISSN 0120-0011. 
Gallego, D.Y.; Figueroa, J. \& Orozco, C. (2010b) Síndrome de Disfunción Cognitiva de Perros geriátricos. Revista MVZ Córdoba, Vol.15, No.3, pp.2252-2262, ISSN 0122-0268.

Gerlach, M., Ben-Shachar, D., Riederer, P. \& Youdim, M.B. (1994). Altered brain metabolism of iron as a cause of neurodegenerative diseases. Journal of Neurochemistry, Vol.63, No.3, pp. 793-807, ISNN 1471-4159

Gilgun-Sherki, Y.; Melamed, E. \& Offen, D. (2001) Oxidative stress inducedneurodegenerative diseases: the need for antioxidants that penetrate the blood brain barrier. Neuropharmacology, Vol.40, No.8, pp. 959-975, ISNN 0028-3908.

Glade, M. (2010). Oxidative stress and cognitive longevity. Nutrition, Vol.26, pp. 595-603.

Goel A, Kunnumakkara AB, Aggarwal BB. (2008). Curcumin as "Curecumin": from kitchen to clinic. Biochem Pharmacol, Vol.75, pp. 787-809.

Greenwald, R.A. (1990). Superoxide dismutase and catalase as therapeutic agents for human diseases: a critical review. Free Radic. Biol. Med. Vol.8, pp.201- 209.

Guarente, L. (2001). SIR2 and aging--the exception that proves the rule. Trend Genet, Vol.17, pp.391-392.

Halliwell, B. (1994). Free radicals, antioxidants, and human disease: curiosity, cause or consequence? The Lancet, Vol.344, No. 8924, pp. 721-724, ISSN 0140-6736.

Halliwell, B. (1997). Antioxidants: the basics - what they are and how to evaluate them. Advances in Pharmacology, Vol.38, pp. 3-20, ISSN ISSN: 0568-0123.

Halliwell, B. (2001). Role of free radical in the neurodegenerative diseases. Drugs $\mathcal{E}$ Aging, Vol. 18, 685-716, ISNN 1170-229X.

Han, M.K., 2003. Epigallocatechin gallate, a constituent of green tea, suppresses cytokineinduced pancreatic beta-cell damage. Exp. Mol. Med. 35, 136-139.

Hayflick, L. (1993). Theories biological Aging. Experimental Gerontology, Vol.20, pp.145-159, ISSN 0531-5565.

Head, E.; Liu, J.; Hagen, T.M.; Muggenburg, B.A.; Milgram, N.W. et al. (2002). Oxidative damage increases with age in a canine model of; human brain aging. Journal of Neurochemistry, Vol.82, No.2, pp.375-81.

Hellenbrand W, Boeing H, Robra B-P, Seidler A, Vieregge P, Nischan P, et al. (1996). Diet and Parkinson's disease II: a possible role for the past intake of specific nutrients. Neurology, Vol.47, pp.644-50.

Heo, H.J. \& Lee, C.Y. (2004). Protective effects of quercetin and vitamin C against oxidative stress-induced neurodegeneration. J. Agric. Food Chem, Vol.52, pp.7514-7517.

Hou, R.R.; Chen, J.Z.; Chen, H.; Kang, X.G.; Li, M.G. \& Wang, B.R. (2008). Neuroprotective effects of (-)-epigallocatechin-3-gallate (EGCG) on paraquat-induced apoptosis in PC12 cells. Cell Biol.Int, Vol.32, pp. 22-30.

Hyman, B.T.; Van Horsen, G.W.; Damasio, A. R. \& Barnes, C.L. (1984). Alzheimer's disease: cell-specific pathology isolates the hippocampal formation. Science, Vol.225, No.4667, pp.168-1170, ISSN 1095-9203.

Izumi, Y.; Sawada, H.; Sakka, N.; Yamamoto, N.; Kume, T.; Katsuki, H.; Shimohama, S. \& Akaike, A. (2005). p-Quinone mediates 6-hydroxydopamine-induced dopaminergic neuronal death and ferrous iron accelerates the conversion of p-quinone into melanin extracellularly. J. Neurosci. Res, Vol.79, pp.849-860.

James JA, Shukitt-Hale B, Denisova NA, Bielinski D, Martin A, McEwen JJ. \& Bickford PC. (1999). Reversals of age-related declines in neuronal signal transduction, cognitive, and motor behavioral deficits with blueberry, spinach, or strawberry dietary supplementation. J Neurosci, Vol.19, pp.8114 - 8121. 
Jang, J.H. \& Surh, Y.J. (2003). Protective effect of resveratrol on beta-amyloidinduced oxidative PC12 cell death. Free Radic. Biol. Med, Vol.34, pp. 1100-1110.

Johnson, E.M. (1994).Possible role of neuronal apoptosis in Alzheimer's disease. Neurobiol Aging, Vol.2, pp.S187-189.

Joseph, J.A.; Denisova, N.; Fisher, D.; Bickford, P.; Prior, R. \& Cao, G. (1998). Agerelated neurodegeneration and oxidative stress: putative nutritional intervention. Neurology Clinical, Vol.16, No.3, pp.747-755.

Juliano, L., Pedersen, J.Z., Rotilio, G., Ferro, D., Violi, F. (1995). A potent chain-breaking antioxidant activity of the cardiovascular drug dipyridamole. Free Radic. Biol. Med., Vol.18, pp. 239- 247.

Kagan, V.E. \& Tyurina, Y. (1998). Recycling and Redox Cycling of phenolic Antioxidants. Ann N Y Acad Sci., Vol.20, No.854, pp.425-34.

Kalaria, R.N.; Maestre, G.E.; Arizaga, R.; Friedland, R.P.; Galasko, D.; Hall, K.; Luchsinger, J.A.; Ogunniyi, A.; Perry, E.K.; Potocnik, F.; Prince, M.; Stewart, R.; Wimo, A.; Zhang, Z.X. \& Antuono, P. (2008). Alzheimer's disease and vascular dementia in developing countries: prevalence, management, and risk factors. Lancet Neurology, Vol.7, pp.812-826.

Kamphuisa, J. \& Scheltensb, P. (2010). Can Nutrients Prevent or Delay Onset of Alzheimer's Disease?. Journal of Alzheimer's Disease, Vol.20, pp.765-775, ISSN 1387-2877

Karuppagounder SS, Pinto JT, Xu H, Chen HL, Beal MF \& Gibson GE. (2008). Dietary supplementation with resveratrol reduces plaque pathology in a transgenic model of Alzheimer's disease. Neurochem Int, Vol.54, pp.111-118.

Kedar, N.P. (2003). Can we prevent Parkinson's and Alzheimer's disease. J Postgrad Med, Vol.49, pp.236-245.

Kelsey, N.; Wilkins, H. \& Linseman, D. (2010). Nutraceutical Antioxidants as Novel Neuroprotective Agents. Molecules, Vol.15, No.11, pp. 7792-7814, ISSN 1420-3049.

Kiziltepe U, Turan NN, Han U, Ulus AT. \& Akar F. (2004). Resveratrol, a red wine polyphenol, protects spinal cord from ischemia-reperfusion injury. J Vasc Surg , Vol.40, pp.138-45.

Kontush A.; Mann U, Arlt S, Ujeyl A, Luhrs C, Muller-Thomsen T, et al. (2001). Influence of vitamin $\mathrm{E}$ and $\mathrm{C}$ supplementation on lipoprotein oxidation in patients with Alzheimer's disease. Free Radic Biol Med, Vol.31, pp.345-354.

Kontush, K. \& Schekatolina, S. (2004). Vitamin E in neurodegenerative disorders: Alzheimer's disease. Ann N Y Acad Sci, Vol.1031, pp.249-262.

Kumar A \& Singh A. (2008). Possible nitric oxide modulation in protective effect of Curcumin (Curcuminlonga, Zingiberaceae) against sleep pdeprivation induced behavioural alterations and oxidative damage in mice. Phytomedicine, Vol.15, pp.577-586.

Landsberg, G. (2005). Therapeutic agents for the treatmen of cognitive dusfunction syndrome in senior dogs. Prog Neuropsychopharmacol Biol Psychiatry, Vol.29, No.3, pp.471-479.

Leibson, C.L.; Rocca, W.A.; Hanson, A.; Cha, R.; Kokmen, E.; O'Brien, P.C. \& Palumbo PJ. (1997). The risk of dementia among persons with diabetes mellitus: a populationbased cohort study. Annals of the New York Academy of Sciences, Vol.826, pp.422-427.

Levites, Y., Weinreb, O., Maor, G., Youdim, M.B. \& Mandel, S. (2001). Green tea polyphenol (-)-epigallocatechin-3-gallate prevents N-methyl-4-phenyl-1,2,3,6- 
tetrahydropyridine-induced dopaminergic neurodegeneration. J. Neurochem, Vol.78, pp.1073-1082.

Levites, Y., Amit, T., Youdim, M.B. \& Mandel, S. (2002). Involvement of protein kinase $\mathrm{C}$ activation and cell survival/cell cycle genes in green tea polyphenol (-)-epigallocatechin 3-gallate neuroprotective action. J. Biol. Chem, Vol. 277, pp.30574-30580.

Li, L., Carter, J., Gao, X., Whitehead, J., Tourtellotte, W.G. (2005). The neuroplasticityassociated arc gene is a direct transcriptional target of early growth response (Egr) transcription factors. Mol. Cell Biol, Vol.25, pp. 10286-10300.

Lim GP, Chu T, Yang F, Beech W, Frautschy SA, Cole GM. (2001).The curry spice curcumin reduces oxidative damage and amyloid pathology in an Alzheimer transgenic mouse. J Neurosci, Vol.21, pp.8370-8377.

Lindsay, J., Laurin, D., Verreault, R., Hebert, R., Helliwell, B., Hill, G.B., McDowell, I. (2002). Risk factors for Alzheimer's disease: a prospective analysis from the Canadian Study of Health and Aging. Am. J. Epidemiol, Vol.156, pp. 445-453.

Luo Y, Smith JV, Paramasivam V, Burdick A, Curry KJ, Buford JP, et al. (2002). Inhibition of amyloid-beta aggregation and caspase-3 activation by the Ginkgo biloba extract EGb761. Proc Natl Acad Sci USA, Vol.99, pp.12197-202.

Mandel, S.; Gr “ unblatt, E.; Riederer, P.; Gerlach, M.; Levites, Y. \& Youdim, M. (2003). Neuroprotective Strategies in Parkinson's Disease An Update on Progress. CNS Drugs, Vol.17, No10, pp.729-762.

Mandel, S. \& Youdim, M.B. (2004). Catechin polyphenols: neurodegeneration and neuroprotection in neurodegenerative diseases. Free Radic Biol Med, Vol.37, pp.30417.

Marambaud, P.; Zhao, H. \& Davies, P. (2005). Resveratrol promotes clearance of Alzheimer's disease amyloid-beta peptides. J Biol Chem, Vol.280, No.45, pp.37377-82.

Marcocci L, Maguire JJ, Droy-Lefaix MT. \& Packer L. (1994). The nitric oxide-scavenging properties of G. biloba extract EGb 761. Biochem Biophys Res Commun, Vol.201, pp.748-55.

Martin, A.; Janigian, D.; Shukitt-Hale, B., et al. Effect of vitamin E intake on levels of vitamins $E$ and $C$ in the central nervous system and peripheral tissues: implications for health recommendations. Brain Res, Vol.845, No.1, pp.50-59

Martínez, J.; Boll-Woehrlen, C.; Hernández, A.; Rubio, M.; Sánchez, M.; Ríos, C. \& Pérez, F. (2010). Radicales libres y estrés oxidativo en las enfermedades neurodegenerativas. Mensaje Bioquímico, Vol.34, pp. 43-59, ISSN -0188-137X.

Martinez, M.; Hernandez, A.I. \& Martinez. (2000). N-acetylcysteine delays age-associated memory impairment in mice: role in synaptic mitochondria. Brain Research, Vol.855, No.1, pp. 100-106, ISSN 00068993

Masaki, K.H., White, L.R. \& Petrovich, H. (1994) The influence of prior and concurrent use of aspirin and vitamins on cognitive function scores in elderly Japanese-American men. Fourth International Conference on Alzheimer's disease and Related disorders", Neurobiology of Aging 15, S1, Fourth International Conference on Alzheimer's disease and Related disorders.

Maurer K, Ihl R, Dierks T, Frölich L. (1997). Clinical efficacy of G. biloba special extract EGb 761 in dementia of the Alzheimer type. J Psychiat Res, Vol.31, pp.645-55. 
Mazzio, E.; Close, F. \& Soliman K. (2011). The Biochemical and Cellular Basis for Nutraceutical Strategies to Attenuate Neurodegeneration in Parkinson's Disease Int. J. Mol. Sci, Vol.12, pp.506-569

McCaddon, Homocysteine and cognitive impairment; a case series in a General Practice setting, Nutr J 5 (2006), 6.

McCay, P.B. (1985). Vitamin E: interactions with free radicals and ascorbate. Annu Rev Nutr, Vol.5, pp. 322-40.

Meydani, M.; Lipman, R.D.; Han, S.N.; Wu, D.; Eharka, A.; Martin, K.R.; Brosnson, R.L., Cao, G.; Smith, D. \& Meydani, S.N. (1998). The Effect of Long-term Dietary Supplementation with Antioxidant. Annals of the New York Academy of Science,Vol.854, pp. 352-360.

Milgram, N.W.; Zicker, S.C.; Head, E.; Muggenburg, B.A.; Murphey, H.; Ikeda-Douglas, C et al. (2002). Dietary enrichment counteracts age-associated cognitive dysfunction in canines. Neurobiology Aging, Vol.23, pp.737-745.

Miloso, M., Bertelli, A.A., Nicolini, G. \& Tredici, G. (1999). Resveratrol-induced activation of the mitogen-activated protein kinases, ERK1 and ERK2, in human neuroblastoma SH-SY5Y cells. Neurosci. Lett, Vol.264, pp.141-144.

Mix JA \& Crews Jr WD. (2000). An examination of the efficacy of G. biloba extract EGb 761 on the neuropsychologic functioning of cognitively intact older adults. J Altern Comp Med, Vol.6, pp.219-29.

Morel, I., Lescoat, G., Cogrel, P., Sergent,O., Pasdeloup, N., Brissot, P., Cillard, P. \& Cillard, J. (1993). Antioxidant and iron-chelating activities of the flavonoids catechin, quercetin and diosmetin on iron-loaded rat hepatocyte cultures. Biochem. Pharmacol, Vol. 45, pp.13-19.

Morris MC, Evans DA, Bienias JL, et al. (2005). Dietary folate and vitamin B12 intake and cognitive decline among communitydwelling older persons. Arch Neurol, Vol.62, pp.641-645.

Morris, M.C.; Evans, D.A.; Tangney, C.C.; Bienias, J.L.; Wilson, R.S.; Aggarwal, N.T. \& Scherr, P.A. (2005). Relation of the tocopherol forms to incident Alzheimer disease and to cognitive change. Am J Clin Nutr, Vol.81, pp.508-514.

Mullie, P.; Guelinckx1, I.; Clarys, P.; Degrave, E.; Hulens, M.\& Vansant1 G.(2009). Cultural, socioeconomic and nutritional determinants of functional food consumption patterns. European Journal of Clinical Nutrition, Vol. 63, No.11, pp.1290-1296.

Murthy, M.R.V. (2001). Coenzyme-Q and related isoprenoid compounds: biosynthesis, regulation, functions and biomedical implications. In: Mitochondrial Ubiquinone (Coenzyme Q-10): Biochemical, Functional, Medical, and Therapeutic Aspects in Human Health and Diseases, Chopra, R. (Eds.), Prominent Press, pp. 231- 346, Arizona.

Nanjo, F., Goto, K., Seto, R., Suzuki, M., Sakai, M. \& Hara, Y. (1996). Scavenging effects of tea catechins and their derivatives on 1,1-diphenyl-2-picrylhydrazyl radical. Free Radic. Biol. Med, Vol.21, pp. 895-902.

Navarro, A. \& Boveris, A. (2008). Brain mitochondrial dysfunction in aging. IUBMB Life, Vol.60, No.5, pp.308-314, ISSN 1521-6551.

Navarro, A. \& Boveris, A. (2010). Brain mitochondrial dysfunction in aging, neurodegeneration, and Parkinson's disease. Frontiers in Aging neuroscience, Vol.2, No.34, pp.1-11, ISSN 1663-4365. 
Ni Y, Zhao B, Hou J, Xin W. (1996). Preventive effect of G. biloba extract on apoptosis in rat cerebellar neuronal cells induced by hydroxyl radicals. Neurosci Lett, Vol.214, pp.115-118.

Opii, O.; Joshi, G; Head, E.; Milgram, W; Bruce, C.; Muggenburg, A.; Klein, J.; Cotmanb, c. \& Butterfield, A. (2008). Proteomic identification of brain proteins in the canine model of human aging following a long-term treatment with antioxidants and a program of behavioral enrichment: Relevance to Alzheimer's disease. Neurobiology of Aging, Vol.29, pp. 51-70.

Orgogozo, J.M., Dartigues, J.F., Lafont, S., Letenneur, L., Commenges, D., Salamon, R., Renaud, S., Breteler, M.B. (1997). Wine consumption and dementia in the elderly: a prospective community study in the Bordeaux area. Rev. Neurol, Vol.153, pp. 185192.

Ossola B, Kääriäinen TM. \& Männistö, P.T. (2009). The multiple faces of quercetin in neuroprotection. Expert Opin Drug Saf, Vol.8, No.4, pp.397-409

Oyama Y, Chikahisa L, Ueha T, Kanemaru K, Noda K. (1996). G. biloba extract protects brain neurons against oxidative stress induced by hydrogen peroxide. Brain Re, Vol.712, pp.349-52.

Parnham, M.J.; Leyck, S. \& Graf, E.E.A. (1991). The pharmacology of ebselen. Agents Actions, Vol.32, pp.4- 9.

Passeri, M.; Cucinotta, D.; Bonati, P.A.; Iannuccelli, M.; Parnetti, L. \& Senin, U. (1990). Acetyl-L-carnitine in the treatment of mildly demented elderly patients. Int J Clin Pharmacol Res, Vol.10, No.1-2, pp.75-79.

Passos, J.; Nelson, G.; Wang, C.; Richter, T.; Simillion, C.; Proctor, C.; Miwa, S.; Olijslagers, S.; Hallinan, J.; Wipat, A.; Saretzki, G.; Kirkwood, T. \& von Zglinicki, T. (2010). Feedback between p21 and reactive oxygen production is necessary for cell senescence. Molecular Systems Biology, Vol.6, No. 347, pp. 1-14, ISSN 1744-4292.

Pauls, K.P. \& Thompson, J.E. (1980). In vitro simulation of senescente-related membrana damage by ozone-induced lipid peroxidation. Nature, Vol.283, pp. 504-6, ISSN 0028-0836.

Pavón, N.; Vidal, L.; Blanco, L.; Á, P.; Torres A.; Lorigados, L.; Álvarez, L.; Macías, R. (1998). Factores que desencadenan la muerte neuronal en enfermedades neurodegenerativas. Revista de Neurología, Vol.26, No.152, pp.554-560, ISSN 0210-0010.

Pérez, A.; Abilés, J \& Castaño, J. (2008). Estrés oxidativo y su implicación en distintas patologías. Nutrición clínica en Medicina, Vol.2, No.2, pp. 45-64, ISSN 1889-1332

Peter, P.Z.; James, C.; Anthon, A.; Khachaturian, S.; Stone, V.; Deborah, G.; JoAnn, T.; Tschanz, M.C.: Norton, K.A. \& John C.S.(2004) Reduced risk of Alzheimer disease in users of antioxidant vitamin supplements-The Cache County Study. Archives of Neuroogy, Vol.61, pp.82-88, ISSN 0375-8540.

Peterson, R.C.; Ronaldhomas, G.; Grundman, M.; Bennett, D.; Doody, R.; Ferris, S.; Galasko, D.; Jin, S.; Kaye, J.; Levey, A.; Pfeiffer, E.; Sano, M.; Christopher, H.; Dyck, V. \& Thal, L.J. (2005). Vitamin E and Donepezil for the treatment of mild cognitive impairment. The N Eng J Med, Vol.353, pp. 2379-2388.

Pillai SR, Traber MG, Steiss JE, Kayden HJ \& Cox NR (1993). Alphatocopherol concentrations of the nervous system and selected tissues of adult dogs fed three levels of vitamin E. Lipids, Vol. 28, pp.1101-1105. 
Poon, H.F.; Calabrese, V.; Calvani, M. \& Butterfield, D.A. (2006). Proteomics analyses of specific protein oxidation and protein expression in aged rat brain and its modulation by L-acetylcarnitine: Insights into the mechanisms of action of this proposed therapeutic agent for CNS disorders associated with oxidative stress. Antioxid Redox Signal, Vol.8, pp.381-94.

Poon, H.F.; Calabrese, V.; Calvani, M.\& Butterfield, D.A.(2006). Proteomics analyses of specific protein oxidation and protein expression in aged rat brain and its modulation by L-acetylcarnitine: Insights into the mechanisms of action of this proposed therapeutic agent for CNS disorders associated with oxidative stress. Antioxid Redox Signal, Vol.8, pp.381-94.

Prasad, K.N.; Cole, W.C. \& Kumar, B. (1999). Multiple Antioxidants in the Prevention and Treatment of Parkinson's Disease. Journal of the American College of Nutrition, Vol.18, No.5, pp.413-423, ISSN 0731-5724

Rahman M, Riaz M. \& Desai U.R. (2001). Synthesis of biologically relevant biflavanoids--a review. Chem Biodivers, Vol.4, pp.2495-2527.

Rao, A.V. \& Balachandran, A. (2002). Role of Oxidative Stress and Antioxidants in Neurodegenerative Diseases. Nutritional Neuroscience, Vol.5, No.5, pp. 291-309.

Ramacci, M.T.; De Rossi, M.; Lucreziotti, M.R.; Mione, M.C. \& Amenta, F. (1998). Effect of long-term treatment with acetyl-L-carnitine on structural changes of ageing rat brain. Drugs Exp Clin Res, Vol.14, pp.593-601.

Ramassamy, C. (2006). Emerging role of polyphenolic compounds in the treatment of neurodegenerative diseases: A review of their intracellular targets. European Journal of Pharmacology, Vol.545, pp.51-64

Ramassamy, C.; Doggui, S.; Arseneault, M. \& Dao, L. (2010). Towards a nutritional approach for the prevention of Alzheimer's disease: Promise of polyphenolic components. Recent Advances on Nutrition and the Prevention of Alzheimer's Disease, Ramassamy, C \& Bastianetto, S (Ed), pp.1-18, ISBN: 978-81-7895-470-7

Ramsewak RS, DeWitt DL, Nair MG.(2000). Cytotoxicity, antioxidant and anti-inflammatory activities of curcumins I-III from Curcuma longa. Phytomedicine, Vol.7, pp.303-308

Resnick B \& Junlapeeya P. (2004). Falls in a community of older adults: findings and implications for practice. Application of Nursing Research, Vol.17, pp.81-91.

Rezai-Zadeh, K.; Arendash, G.W.; Hou, H.; Fernandez, F.; Jensen, M.; Runfeldt, M.; Shytle, R.D. \& Tan, J.(2008). Green tea epigallocatechin-3-gallate (EGCG) reduces betaamyloid mediated cognitive impairment and modulates tau pathology in Alzheimer transgenic mice. Brain Res, Vol.1214, pp.177-187.

Rivas, A.S.; Colín, L.; Dorado, C. \& Fortoul, T. (2001). Estrés oxidativo y neurodegeneración, In: temas selectos de neurociencias II, J. Velázquez (Ed.), UNAM-PUIS, México, ISBN 970-654-850-5.

Sales, I.; Rocha, A.; Barros, G.; Pinheiro, P. Ferreira, P. \& Mendes, R. (2009). Oxidative stress in the hippocampus during experimental seizures can be ameliorated with the antioxidant ascorbic acid. Oxidative Medicine and Cellular Longevity, Vol.2, No.4, pp.214-221.

Sano M, Ernesto C, Klauber MR, Schafer K, Woodbury P, Thomas R, et al . (1996). Rationale and design of a multicenter study of selegilina and alpha-tocopherol in the treatment of Alzheimer disease using novel clinical outcomes. Alzheimer's Disease Cooperative Study. Alzheimer Dis Assoc Disord, Vol.10, pp.132-140. 
Sano M, Ernesto C, Thomas RG, Klauber MR, Schafer K, Grundman M, et al. (1997). A controlled trial of selegiline, alphatocopherol, or both as treatment for Alzheimer's disease. The Alzheimer's Disease Cooperative Study. N Engl J Med, Vol.336, pp.1216-1222.

Sasaki, N.; Toda, T.; Kaneko, T.; Baba, N. \& Matsuo, M. (2003). Protective effects of flavonoids on the cytotoxicity of linoleic acid hydroperoxide toward rat pheochromocytoma PC12 cells. Chem. Biol. Interact. Vol.145, pp.101-116.

Scalbert A, Johnson IT \& Saltmarsh, M. (2005). Polyphenols: antioxidants and beyond. Am J Clin Nutr, Vol.81, pp.215S-7S.

Seshadri, S. \& Wolf, P.A. (2003). Homocysteine and the brain: vascular risk factor or neurotoxin? Lancet Neurol, Vol.2, No.11

Sharman, E.H.; Vaziri, N.D.; Ni, Z.; Sharman, K.G. \& Bondy, S.C. (2002). Reversal of biochemical and behavioral parameters of brain aging by melatonin and acetyl Lcarnitine. Brain Res, Vol.957, pp. 223-30.

Silva, J.P.; Gomes, A.C. \& Coutinho, O.P. (2008). Oxidative DNA damage protection and repair by polyphenolic compounds in PC12 cells. Eur. J. Pharmacol, Vol.601, pp.5060.

Sohal, R.S. (1993). The free radical hypothesis of aging: an appraisal of the current status. Aging Clinical and Experimental Research, Vol.5, No.1, pp.3-17, ISSN 1594-0667.

Sun, A.; Wang, Q.; Simonyi, A.. \& Sun, G. (2008). Botanical phenolics and brain health. Neuromolecular Medicine, Vol.10, No.4, pp, 259-274.

Sung S, Yao Y, Uryu K, Yang H, Lee VM, Trojanowski JQ, et al. (2004). Early vitamin E supplementation in young but not aged mice reduces Abeta levelsand amyloid deposition in a transgenic model of Alzheimer's disease. FASEB J, Vol.18, pp.323-5.

Tamura, M.; Kagawa, S.; Tsuruo, Y.; Ishimura, K.\& Morita, K. (1994). Effects of flavonoid compounds on the activity of NADPH diaphorase prepared from the mouse brain. Jpn. J. Pharmacol, Vol.65, pp. 371-373.

Terry, R.D.; Masliah, E.; Salmon, D.P.; Butters, N.; DeTeresa, R.; Hill, R.; Hansen, L.A. \& Katzman, R. (1991). Physical basis of cognitive alterations in Alzheimer's disease: synapse loss is the major correlate of cognitive impairment. Annals of Neurolology, Vol.30, No.4, pp. 572-580, ISSN 0364-5134.

Truelsen, T., Thudium, D., Gronbaek, M. (2002). Amount and type of alcohol and risk of dementia: the Copenhagen City Heart Study. Neurology, Vol.59, pp.1313-1319.

Tucker KL, Qiao N, Scott T, et al. (2005). High homocysteine and low B vitamins predict cognitive decline in aging men: the Veterans Affairs Normative Aging Study. Am J Clin Nutr, Vol.82, pp.627-35.

Valko, M.; Leibfritz, D.; Moncola, J.; Cronin, M.; Mazura, M. \& Telser, J. (2007). Free radicals and antioxidants in normal physiological functions and human disease. The International Journal of Biochemistry \& Cell Biology, Vol. 39, No.1, pp.44-84, ISSN 1357-2725.

Vatassery GT, Brin MF, Fahn S, Kayden HJ \&Traber MG. (1988). Effect of high doses of dietary vitamin $\mathrm{E}$ on the concentrations of vitamin $\mathrm{E}$ in several brain regions, plasma, liver, and adipose tissue of rats. J Neurochem, Vol.51, pp.621-623.

Vermeer, S.E.; Prins, N.D.; denHeijer, T.; Hofman, A.; Koudstaal, P.J. \& Breteler, M.M. (2003). Silent brain infarcts and the risk of dementia and cognitive decline. New England Journal of Medicine, Vol.3, No.348, pp.1215-1222, ISSN 1533-4406. 
Viant, D.; Fonseca, C. \& Ileana, C. (1999). Radicales libres y su papel en la homeostasia neuronal. MEDISAN, Vol.3, No3, pp. 5-11, ISSN 1029-3019

Virgili M \& Contestabile A. (2000). Partial neuroprotection of in vivo excitotoxic brain damage by chronic administration of the red wine antioxidant agent, transresveratrol in rats. Neurosci Lett, Vol.281, pp.123-6.

Wang HX, Wahlin A, Basun H, et al. (2001). Vitamin B(12) and folate in relation to the development of Alzheimer's disease. Neurology, Vol.56, pp.1188-94.

Weinreb, O.; Mandel, S.; Amit, T. \& Youdim, M.B. (2004). Neurological mechanisms of green tea polyphenols in Alzheimer's and Parkinson's diseases. J. Nutr. Biochem, Vol.15, pp.506-516.

Witschi. A.; Reddy, S.; Stofer, B. \& Lauterburg, B.H. (1992). The systemic availability of oral glutathione. European Journal of Clinical Pharmacology, Vol.43, pp.667-669.

Xin W, Wei T, Chen C, Ni Y, Zhao B, Hou J. (2000). Mechanisms of apoptosis in rat cerebellar granule cells induced by hydroxyl radicals and the effects of EGb 761 and its constituents. Toxicology, Vol.148, pp.103-10.

Yao Z, Drieu K \& Papadopoulos V. (2001). The Ginkgo biloba extract EGb 761 rescues the PC12 neuronal cells from beta-amyloid-induced cell death by inhibiting the formation of beta-amyloid-derived diffusible neurotoxic ligands. Brain Res, Vol.889, pp.181-90.

Zandi PP, Anthony JC, Khachaturian AS, Stone SV, Gustafson D, Tschanz JT, et al. (2004). Reduced risk of Alzheimer disease in users of antioxidant vitamin supplements: the Cache County Study. Arch Neurol, Vol.61, No.1, pp. 82-8

Zhao, W., Richardson, J.S., Mombourquette, M.J. \& Weil, J.A. (1995). An in vitro EPR study of the free-radical scavenging actions of the lazaroid antioxidants U-74500A and U78517F. Free Radic. Biol. Med., Vol.19, pp.21- 30.

Zimmermann, A.K.; Loucks, F.A.; Schroeder, E.K.; Bouchard, R.J.; Tyler, K.L. \& Linseman, D.A. (2007). Glutathione binding to the Bcl-2 homology-3 domain groove: a molecular basis for Bcl-2 antioxidant function at mitochondria. J. Biol. Chem, Vol.282, pp.29296-29304. 
NEURODEGENERATIVE DISEASES

PROCESSES, PREVENTION, PROTECTION

AND MONITORING

Ested by Raymond Owen-Chune Chane

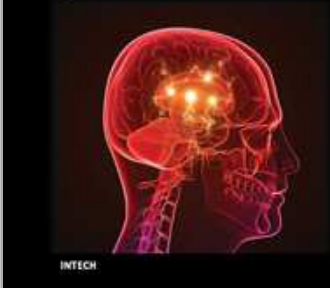

\section{Neurodegenerative Diseases - Processes, Prevention, Protection and Monitoring}

Edited by Dr Raymond Chuen-Chung Chang

ISBN 978-953-307-485-6

Hard cover, 558 pages

Publisher InTech

Published online 09, December, 2011

Published in print edition December, 2011

Neurodegenerative Diseases - Processes, Prevention, Protection and Monitoring focuses on biological mechanisms, prevention, neuroprotection and even monitoring of disease progression. This book emphasizes the general biological processes of neurodegeneration in different neurodegenerative diseases. Although the primary etiology for different neurodegenerative diseases is different, there is a high level of similarity in the disease processes. The first three sections introduce how toxic proteins, intracellular calcium and oxidative stress affect different biological signaling pathways or molecular machineries to inform neurons to undergo degeneration. A section discusses how neighboring glial cells modulate or promote neurodegeneration. In the next section an evaluation is given of how hormonal and metabolic control modulate disease progression, which is followed by a section exploring some preventive methods using natural products and new pharmacological targets. We also explore how medical devices facilitate patient monitoring. This book is suitable for different readers: college students can use it as a textbook; researchers in academic institutions and pharmaceutical companies can take it as updated research information; health care professionals can take it as a reference book, even patients' families, relatives and friends can take it as a good basis to understand neurodegenerative diseases.

\section{How to reference}

In order to correctly reference this scholarly work, feel free to copy and paste the following:

Diana Gallego, Manuel Rojas and Camilo Orozco (2011). Free Radicals, Neuronal Death and Neuroprotection, Neurodegenerative Diseases - Processes, Prevention, Protection and Monitoring, Dr Raymond Chuen-Chung Chang (Ed.), ISBN: 978-953-307-485-6, InTech, Available from:

http://www.intechopen.com/books/neurodegenerative-diseases-processes-prevention-protection-andmonitoring/free-radicals-neuronal-death-and-neuroprotection

\section{INTECH}

open science | open minds

\section{InTech Europe}

University Campus STeP Ri

Slavka Krautzeka 83/A

51000 Rijeka, Croatia

Phone: +385 (51) 770447

Fax: +385 (51) 686166

\section{InTech China}

Unit 405, Office Block, Hotel Equatorial Shanghai

No.65, Yan An Road (West), Shanghai, 200040, China 中国上海市延安西路65号上海国际贵都大饭店办公楼 405 单元

Phone: +86-21-62489820

Fax: +86-21-62489821 
www.intechopen.com 
(C) 2011 The Author(s). Licensee IntechOpen. This is an open access article distributed under the terms of the Creative Commons Attribution 3.0 License, which permits unrestricted use, distribution, and reproduction in any medium, provided the original work is properly cited. 